\title{
3 Vom Produkt zur Firma, von der Dritten Welt zur Umwelt (1973-1977)
}

\section{1 „Die Abkopplung“: die Grenzen des Wachstums, Small is beautiful, Jute statt Plastik}

In der Schweiz der 1970er-Jahre, also in „The Age of Alternatives“, gab die Editionsgemeinschaft Dezentrale in Pruntrut die sogenannten „Alternativkataloge“ heraus. ${ }^{1}$ Diese sind Zeugen und Abbild der damaligen Geisteshaltung der alternativen Bewegung der Schweiz. In den Katalogen wurden stets Themen kurz zusammengefasst, die von Aktivistinnen und Aktivisten diskutiert wurden. Gemäss deren Anspruch, klar, kurz und knapp zu sein und sozusagen ein Lexikon oder einen Kanon der Alternativkultur zu schaffen, bringen die verschiedenen Artikel zum Nord-Süd-Verhältnis im „Alternativkatalog“ die Grundeinstellung auf den Punkt, welche die Dritte-Welt-Bewegung zu multinationalen Firmen und Direktinvestitionen hatte. Multinationale Konzerne und Direktinvestitionen in Entwicklungsländern werden unter dem Begriff „Imperialismus“ abgehandelt. ${ }^{2}$ Klar erkennbar ist der Bezug auf die Imperialismustheorie Johan Galtungs und Dieter Senghaas'. ${ }^{3}$ Unter dem Titel „Wirtschaftlicher Imperialismus“ schrieb die Editionsgemeinschaft Dezentrale basierend auf einem Arbeitspapier der Zürcher Arbeitsgruppe Dritte Welt Folgendes:

\footnotetext{
Wirtschaftlicher Imperialismus hilft den Herrschenden, ihre Macht zu halten. Kapitalexporte gleichen die Schwankungen der Investitionen der Industrieländer im Inland aus und tragen damit zu einer Stabilisierung des Wachstums bei. Auf diese Weise können auch Rohstoffe gesichert werden, die Absatzmärkte kontrolliert, die Expansion vergrössert, die Produktion im Ausland kontrolliert, die Profite erhöht und die Konkurrenz überrundet werden. ${ }^{4}$
}

Auf diese Definition folgt ein fliessender Übergang zur Theorie der „Abkopplung“ und zur „Peripherie im Inland“, wie sie bei Galtung und Senghaas zu finden war. ${ }^{5}$

1 M. Black: Oxfam the First 50 Years, 132, Dezentrale: Alternativ-Katalog 3. Gemäss B. Mahler: ,umdenken - umschwenken' gab das Gottlieb-Duttweiler-Institut in Rüschlikon den ersten Katalog heraus. Danach übernahm die Dezentrale, die jedoch den zweiten Band in Köniz und den dritten Band in Basel herausgab. Erst die weiteren Auflagen wurden von der Dezentrale in Porrentruy herausgegeben.

2 Dezentrale: Alternativ-Katalog 3, 569.

3 M. Schär: Strukturveränderungen statt Entwicklungshilfe, 33-38.

4 Dezentrale: Alternativ-Katalog 3, 569.

5 M. Schär: Strukturveränderungen statt Entwicklungshilfe, 33-38.

Ә OpenAccess. (C) 2020 Andrea Franc, publiziert von De Gruyter. (cc) BY-NC-ND Dieses Werk ist lizenziert unter der Creative Commons Attribution-NonCommercial-NoDerivatives 4.0. 
Eine Massnahme gegen den Imperialismus sei etwa die „selbstständigere und isolierte Entwicklung, so dass die Entwicklungsländer ihre Präferenzen durchsetzen können““. ${ }^{6}$ Der „grundlegenden Tatsache“, dass ,jedes Land auf Warenaustausch angewiesen ist" und sich somit nicht isolieren kann, hatte die Bewegung nun abgeschworen. ${ }^{7}$ Sie ging nun davon aus, dass private Direktinvestitionen in Entwicklungsländer stets eine Beziehung zwischen zwei Zentren waren, wobei die „Peripherie im Inland“ sowie die Peripherie des Entwicklungslandes geschädigt wurden. Die Thesen zum ,wirtschaftlichen Imperialismus“ leiten denn auch zur Erklärung über, wie Solidarität zwischen den zwei Peripherien ausgestaltet werden könnte. So wird auf der nächsten Seite des „Alternativkatalogs“ ein Kurzbeschrieb der EvB aufgeführt, die sich und ihr Konzept der Solidarität zwischen den Peripherien als Vorschlag anpreist, wie dem „Wirtschaftlichen Imperialismus“ zu begegnen sei. ${ }^{8}$ Die von Anne-Maire Holenstein verfasste Kurzbeschreibung der Zielsetzung der EvB zeigt auf, in welche Richtung sich das Fair-Trade-Konzept entwickeln sollte und wie es ursprünglich als Antithese zu den „Praktiken der europäischen Konzerne in der dritten Welt“ gedacht war. So schreibt die EvB:

Wir setzen uns für angepasste und arbeitsintensive technische Lösungen ein als Alternative zu den kapitalintensiven und ökologisch fragwürdigen Methoden der Industrie. ${ }^{9}$

Hier scheinen bereits viele Aspekte auf, die sich später durchsetzen und die Prägung des Fair-Trade-Konzepts durch die marxistisch-leninistische Imperialismustheorie vergessen machten. So der Rückgriff auf E.F. Schumachers Forderung der Anpassung der Technologie an die Bedürfnisse der Entwicklungsländer. ${ }^{10}$ Schumacher selbst war sich stets bewusst, dass seine Modelle gerade bei den Aktivisten der 68er-Generation auf fruchtbaren Boden fielen. Er hatte in Grossbritannen denn auch eine Forschugsstelle für angepasste Technologien gegründet:

Die Aufgabe, die wir uns gestellt haben, ist, eine ,mittlere‘, ,angepasste‘, dem kleinen Mann und den unzähligen Armen der Welt zugängliche, auf echte menschliche Grössenverhältnisse berechnete Technik zu entwickeln. Den ersten Anstoss zu dieser - rein freiwilligen und nicht auf's Geld verdienen angelegten - Arbeit war die sich stetig verschärfende Krise in den sogenannten Entwicklungsländern, die durch die wahllose Übertragung der modernen Su-

6 Dezentrale: Alternativ-Katalog 3, 569.

7 H. Schmocker, M. Traber: Schweiz-Dritte Welt, 103.

8 Dezentrale: Alternativ-Katalog 3, 571.

9 Ebd.

10 E. F. Schumacher: Es geht auch anders, 119. 
pertechnik eher zerstört als gefördert werden. Es hat sich dann bald herausgestellt, dass nicht nur die armen, sondern auch die reichen Länder eine dem Menschen angepasste Technik dringedst benötigen, und dass es überall Gruppen gibt, die nach einer solchen Technik verlangen. ${ }^{11}$

Im von der EvB vertriebenen Buch „Zerstörung duch Überfluss“ wird Schumachers „Es geht auch anders“ (1974) denn auch ausführlicher zitiert. ${ }^{12}$ Im Beschreib der EvB findet sich zudem der Begriff ,,arbeitsintensiv“, der zu einem Hauptpfeiler der Entwicklungsökonomie der 1970er-Jahre wurde und noch auf dem keynesianischen Ideal des full employment basierte. Demnach teilte das Konzept der arbeitsintensiven Industrialisierung die Bevölkerung der Dritten Welt noch ohne jeglichen Kulturrelativismus gemäss westlichen Standards in Beschäftigte und Arbeitslose ein. ${ }^{13}$ Ferner steht im Kurzbeschrieb der EvB der Begriff „ökologisch“, der sich später zum Primat entwickeln sollte. ${ }^{14}$ Die EvB beschreibt auch hier die „Alternative“ zur Kapitalinvestition und zur europäischen Industrie. Die Grundlage für das spätere Fair-Trade-Konzept, das ohne Kapitalinvestition und ohne europäische Industrie auskommen würde, wurde hier gelegt. So war es der Bewegung denn auch möglich, sich auf Jean Zieglers Buch „Une Suisse au-dessus de tout soupçon“ (1976) zu berufen, das sich im Gegensatz zu vielen anderen Schweizer Schriften klar und ausdrücklich auf die marxistisch-leninistische Imperialismustheorie stützt. ${ }^{15}$ Unterstützt wurde die neue Forderung nach Abkopplung der Entwicklungsländer von der Weltwirtschaft von der Umweltbewegung der 1970er-Jahre.

Kurz nach dem Manifest von 1968 erstarkte in der Schweiz die Umweltbewegung, allerdings zunächst auf bürgerlicher Seite. Die Entwicklung im Umweltschutz auf staatlicher Ebene deckte sich hierzulande mit derjenigen im Nichtregierungsbereich. Die Autoren der britischen DANGO-Studien stellten denn auch für Grossbritannien fest, dass die Entwicklung von Nichtregierungsorganisationen komplementär zum Staatsauf- und Ausbau verlief. ${ }^{16}$ Diese Beobachtung trifft auch auf die Schweiz zu. So erfolgte bereits 1971 die Schaffung des Bundesamts für Umwelt und 1976 die Gründung eines Bundesamts für Entwicklungshilfe. Schon 1970 gab es an der Universität Zürich eine Studentengruppe für

11 Ebd., 51.

12 A.-M. Holenstein, J. Davis: Zerstörung durch Überfluss, 79.

13 G. Austin: The Developmental State.

14 Siehe Kapitel 3.4. Von der Dritten Welt zur Umwelt: die Neuausrichtung der Theologen der Anfangsjahre.

15 J. Wegelin: Jean Ziegler, 63-70, J. Ziegler: Une Suisse au-dessus.

16 M. Hilton: Politics of Expertise, 191-197. 
Umweltschutz. ${ }^{17}$ Diese stand jedoch nicht in Konflikt mit der Vätergeneration, vielmehr stimmte sie inhaltlich grösstenteils mit ihr überein. So erhielt das Umweltschutzgesetz 1971 eine nie dagewesene hohe Zustimmung, vielleicht auch dank der Stimmbürgerinnen, die im Juni 1971 erstmals abstimmen durften. Daraufhin erschien 1972 die vom Club of Rome in Auftrag gegeben Studie „The Limits to Growth“, die in St. Gallen erstmals vorgestellt wurde. ${ }^{18} 1973$ erschien Ernst Friedrich Schumachers „Small is Beautiful“, nachdem der Ökonom bereits früher an der ETH Zürich doziert hatte. ${ }^{19} 1974$ erschien Schumachers „Es geht auch anders“, eine Sammlung deutschsprachiger Aufsätze, 1977 die deutsche Übersetzung von „Small is Beautiful“ unter dem Titel „Die Rückkehr zum menschlichen Mass“. ${ }^{20}$ Die Umweltbewegung überrollte die zwar nicht kapitalismus-, aber doch modernisierungsfreundliche Dritte-Welt-Bewegung, der progressive Nord-SüdAnsatz von 1968 verwandelte sich in eine konservative Reaktionsbewegung. ${ }^{21}$

Dieser Reaktionismus der frühen 1970er-Jahre schlug sich auch nieder in der nächsten Kampagne der EvB. Die EvB verschickte Fragebogen an die Aktionsgruppen, die Ujamaa-Pulverkaffee verkauft hatten, und fragte, was für eine Kampagne als Nächstes gestartet werden solle. Klare Siegerin der Umfrage war die Kampagne Jute statt Plastik. ${ }^{22}$ So verkauften dieselben Gruppen, die vorher industriell hergestellten Pulverkaffee unter die Leute gebracht hatten, als nächstes Produkt Jutetaschen aus Bangladesch, die mit dem Aufdruck „Handarbeit“ versehen waren. ${ }^{23}$ Die Basis hatte somit Mitte der 1970er-Jahre ihre Weltanschauung grundlegend umgestellt. Portierte sie im Jahr zuvor noch freiwillig ein afrikanisches Industrieprodukt, votierte sie nun dafür, ein in Handarbeit produziertes Produkt zu verkaufen. Der Slogan ,Jute statt Plastik“ stand nicht nur für mehr Umweltschutz, sondern auch für ein Zurück zur Natur. Auch die feministische Perspektive schwingt mit, da die Säcke von Frauen hergestellt wurden. Wie Kalt aufzeigte, baute die Dritte-Welt-Bewegung „Diskursbrücken“ zur Umwelt- oder

17 U. Eichenberger: Ökologie und Selbstbestimmung, 23.

18 D. H. Meadows, D. L. Meadows, J. Randers, W. W. Behrens: Limits to Growth.

19 U. Eichenberger: Ökologie und Selbstbestimmung, 25, E. F. Schumacher: Small is Beautiful. 20 Schumacher, Ernst Friedrich; McRobie, George: Die Rückkehr zum menschlichen Mass. Alternativen für Wirtschaft und Technik (Reinbek bei Hamburg 1977), E. F. Schumacher: Es geht auch anders.

21 Siehe dazu ähnlich Badinter, Elisabeth: Der Konflikt. Die Frau und die Mutter (München 2010), 46.

22 K. J. Kuhn: Fairer Handel und Kalter Krieg.

23 Kuhn, Konrad J.: ,Das Produkt als Aufhänger für Information und Schulungsarbeit‘. Die Entwicklungspolitische Konsumentenaktion ,Jute statt Plastic', 1976-1979, in: Traverse 12/3 (2005) 27-39. 
Gewerkschaftsbewegung und so auch zum Feminismus. ${ }^{24}$ Implizit zeigt die Entscheidung für die Jutetaschenkampagne auch, wie sich das Bild der Entwicklungsländer geändert hatte. An die Stelle fordernder und souveräner junger Männer mit einem Anspruch auf white collar jobs traten nun analphabetische Frauen ohne Perspektive. Deren Lage sollte nicht radikal und grundlegend geändert, sondern einzig durch den Kauf von Jutetaschen ein bisschen verbessert werden. Das Statische hatte sich in das Bild der Dritten Welt eingeschlichen und die „Dynamik der Hoffnung“, wie sie Jacques Rossel 1967 benannt hatte, verdrängt. ${ }^{25}$ Von der Bildfläche verschwanden die urbanen, intellektuellen, selbstbewussten Männer aus Entwicklungsländern. Sie verschwanden sowohl aus der Wahrnehmung der Dritte-Welt-Bewegung als auch aus dem tatsächlichen Bild der europäischen Universitäten, als die Einkommensschere zwischen Europa und den Ländern des Südens zunehmend aufging, die Bildungsinstitutionen in Entwicklungsländern nicht mehr finanziert werden konnten und sich somit auch die Schere zwischen Studierenden in der Dritten Welt und im Westen zu stark öffnete. $^{26}$

In den 1970er-Jahren verdrängte zudem ein deutscher Denker die südlichen Autoren von der Literaturliste der Schweizer Dritte-Welt-Aktivisten. Dieter Senghaas erhielt 1972 eine Professur an der Universität Frankfurt und war sozusagen ein später Satellit der Frankfurter Schule. Seine Theorien wurden in den 1970er-Jahren im deutschen Sprachraum stark diskutiert. Senghaas veröffentlichte damals mehrere Bücher, die auch in der Schweizer Dritte-Welt-Bewegung stark rezipiert wurden, nämlich „Imperialismus und strukturelle Gewalt“ (1972), „Peripherer Kapitalismus. Analysen über Abhängigkeit und Unterentwicklung“ (1974), „Kapitalistische Weltökonomie. Kontroversen über ihren Ursprung und ihre Entwicklungsdynamik“ (1979) sowie insbesondere „Weltwirtschaftsordnung und Entwicklungspolitik. Plädoyer für Dissoziation“ (1977). ${ }^{27}$ In seinen Werken machte er die deutschsprachige Bewegung mit den Begriffen „Zentrum“ und „Peripherie“ vertraut und plädierte für eine zeitweise Abkopplung (Dissoziation) der Volkswirtschaften der Entwicklungsländer vom Welthandel, um eigene Industrien aufbauen zu können. Der von Johan Galtung geprägte und von Dieter

24 M. Kalt: Tiersmondismus in der Schweiz, 516.

25 J. Rossel: Dynamik der Hoffnung.

26 M. Nobs-Margairaz: L'Institut africain, 73.

27 Senghaas, Dieter; Alavi, Hamza: Kapitalistische Weltökonomie. Kontroversen über ihren Ursprung und ihre Entwicklungsdynamik (Frankfurt am Main 1979), Senghaas, Dieter: Weltwirtschaftsordnung und Entwicklungspolitik. Plädoyer für Dissoziation (Frankfurt am Main 1977), Senghaas, Dieter; Amin, Samir: Peripherer Kapitalismus. Analysen über Abhängigkeit und Unterentwicklung (Frankfurt am Main 1974). 
Senghaas übernommene Begriff der „strukturellen Gewalt“ konnte auch auf die Schweiz angewandt werden, die nie eine Kolonialmetropole gewesen war. ${ }^{28}$

Senghaas übersetze sozusagen die anti-kapitalistischen Theorien, die auf die Dependenztheorie der 1960er-Jahre folgten, ins Deutsche. Insbesondere vertrat er die wirtschaftliche „Abkopplung“ der Entwicklungsländer von der westlichen kapitalistischen Weltwirtschaft. Das decoupling, in seiner sanfteren Form auch self-reliance genannt, war eine maoistische Theorie und sah die eigenständige wirtschaftliche Entwicklung ohne Einbettung in die kapitalistische Weltwirtschaft vor. Es bezeichnete eine marxistische Art der infant industry protection, wobei die infant industry nicht durch westliche Privatinvestitionen in Gang gesetzt und dann lediglich durch temporäre Schutzzölle geschützt wurde, sondern in vollständiger Autarkie erfolgte. ${ }^{29}$ Senghaas' Theorie der Abkopplung harmonierte mit der gleichzeitig laut gewordenen Wachstumskritik und der Aufwertung indigener Produktionsmethoden. Zudem harmonierte die Abkopplungstheorie unmerklich auch mit dem aufkommenden Neoprotektionismus der westlichen Staaten. Wenn Entwicklungsländer sich vom Westen abkoppeln sollten, fiel auch die Bedeutung des Marktzugangs und der eigenen Handelsschranken weg. Vermutlich ungewollt hatte Christoph Eckenstein innerhalb der Schweizer Dritte-Welt-Bewegung mit seinem Pochen auf regionale wirtschaftliche Integration unter den Entwicklungsländern als Steigbügelhalter für Senghaas’ Abkopplung gedient. Regionale wirtschaftliche Integration, Abkopplung und Wachstumskritik dienten allesamt als Argument, um den Abbau der eigenen Handelsschranken zu vernachlässigen. Somit gestaltete sich der im Rückblick als fundamentaler Richtungswechsel erscheinende Wandel im Fair-Trade-Konzept in den 1970er-Jahren fliessend und mit scheinbarer Kohärenz.

Im Rückblick beschreibt Strahm das neue entwicklungspolitisches Konzept der „Abkopplung“:

[Abkopplung] bedeutete die Förderung von Kleinbauern statt des Agrobusiness, die Kontrolle der ausländischen Direktinvestitionen und die Begrenzung der staatlich geförderten Exportkredite, die zur Überschuldung führen mussten..$^{30}$

Interessant ist hier, dass Strahm erst im Nachhinein, in seinen im 21. Jahrhundert verfassten Erinnerungen, den Kleinbauern nennt. In den zeitgenössischen Quellen hingegen taucht der Begriff Kleinbauer zu Beginn der 1970er-Jahre kaum auf. Auch Strahm selbst sprach Mitte der 1970er-Jahre nicht von Kleinbauern, sondern

28 A.-M. Holenstein-Hasler, R. Renschler, R. H. Strahm: Entwicklung heisst Befreiung, 97-98.

29 D. Senghaas: Weltwirtschaftsordnung und Entwicklungspolitik.

30 A.-M. Holenstein-Hasler, R. Renschler, R. H. Strahm: Entwicklung heisst Befreiung, 160. 
von „sozialen Marginalgruppen“ und hatte sich sehr differenziert mit der „Abbkopplungs“-These befasst. ${ }^{31}$ Die „Abkopplung“, die sich in den 1980er-Jahren in eine resignierte Forderung nach Autarkie der Entwicklungsländer weiterführen sollte, hatte Mitte der 1970er-Jahre noch lange nicht vollständig die UNCTADForderung der tiefen Integration der Entwicklungsländer in die Weltwirtschaft verdrängt. Strahm konnte sich auch 1976 noch nicht vollständig von seiner wirtschaftswissenschaftlichen Ausbildung und dem Grundprinzip der Marktwirtschaft lossagen. So erklärte er in einem persönlichen Brief an einen Pfarrer, der ihm vorgeworfen hatte, er sei ein Kommunist, dass dieser irre:

[...] wenn sie glauben, unsere Forderung nach Desintegration der Entwicklungsländer aus der westlichen Weltwirtschaft beinhalte eine Forderung, diese Länder müssten sich in das östliche Wirtschaftssystem integrieren. Dies ist ein völliges Missverständnis. Denn es geht gerade um eine Desintegration aus der allgemeinen Abhängigkeit von der industrialisierten Welt, und zwar mit dem Ziel, eine national integrierte Wirtschaft mit der Orientierung der Produktion auf die internen Bedürfnisse der Bevölkerung aufzubauen. Diese Theorie der Abkoppelung oder der selektiven Teilnahme basiert auf der Analyse, dass die offenen Volkswirtschaften der Entwicklungsländer sozusagen auch nach dem reichen Ausland geöffnete Adern ihrer Wirtschaftsströme enthalten. Es gibt ebenso gute entwicklungspolitische Gründe für eine Abkoppelung, wie für eine Integration in das Weltwirtschaftssystem. ${ }^{32}$

Bis etwa 1975 vertraten die EvB und ihre Basis aus freiwilligen Helferinnen und Helfern in keiner Weise die Idee des Kleinbauern, sondern jene der Industrialisierung Afrikas gemäss dem Ujamaa-Konzept. Danach folgte zunächst die Jutesack-Aktion, die auf urbanem Handwerk basierte, auch wenn die Jute gleichsam ein erster Schritt hin zum bäuerlichen Nahrungsrohstoff war. Wir sehen in Strahms Erinnerung jedoch, wie Senghaas' Theorie der Abkopplung die Bewegung weg von der Prebisch-Singer-These führte, den Fokus auf die „Kapitalexporte“ verschob und diese als Problem benannte. ${ }^{33}$ Damit vollzog die Bewegung in ihrer Position gegenüber Direktinvestitionen wiederum eine Kehrtwende. Noch 1970 hatten die Initianten der „Erklärung von Bern“ der Schweizer Privatwirtschaft vorgeworfen, nicht genug in der Dritten Welt zu investieren. ${ }^{34} 1975$ ging der Vorwurf von Seiten der Arbeitsgemeinschaft der Schweizer Hilfswerke - und somit von einer breit und offiziell abgestützten Gruppierung - in die andere Rich-

31 Strahm, Rudolf H.: Beziehungen Schweiz Dritte Welt: Imperialismus? Gastvorlesung an der Universität Bern (Bern 1974) 10.

32 SozArch, EvB, Ar 430.62.8 IDA. R. Strahm an Pfr. E. J., 11.6.1976.

33 Dezentrale: Alternativ-Katalog 3, 569.

34 SozArch, EvB, Ar 430.25.1. EvB, Anfangszeit, EvB: Die Schweiz und die Entwicklungsländer, Text, der am 14.11.1970 in Bern vom Schweizer Komitee der EvB genehmigt wurde. 
tung: Die Schweizer Privatwirtschaft sollte in der Dritten Welt nicht investieren; dem Staat wurde Komplizenschaft im „passiven Imperialismus“ unterstellt, weil er die Investitionen der privaten Schweizer Firmen mit der 1958 eingeführten Exportrisikogarantie bzw. der 1970 ergänzten Investitionsrisikogarantie auf intransparente Weise unterstützte. ${ }^{35}$

Sehr schnell wurden in den 1970er-Jahren der Umweltschutz und die Wachstumskritik, der Imperativ zur lokalen Produktion im Kleinformat, zum Primat der Dritte-Welt-Bewegung. Der Bedarf der jungen Alternativen verlagerte sich rasch von der Hilfe für die Dritte Welt zu einer dogmatisch anmutenden, korrekten, alternativ-ökologischen Lebensweise. Die Beziehung zur Dritten Welt wurde zu einem Teil des persönlichen Verhaltenskodex, der in erster Linie eine korrekte Lebensweise im eigenen Alltag vorschrieb. Die Anleitung dazu lieferten die Kataloge der Dezentrale, die auf hunderten von Seiten Kurzfassungen zu Verhalten und Haltung im Alltag boten. In der zweiten Hälfte der 1970er-Jahre, als diese Kataloge geschrieben, produziert, verkauft und gelesen wurden, ist das Primat der Ökologie und die starke Rückstufung des Themas Dritte Welt klar erkennbar. So geht es in den ersten zwei Katalogen ausschliesslich um die Themen biologischer Landbau, Energiegewinnung, Hausbau, Transport, Recycling, Leben in Gemeinschaften sowie um die Geschlechterverhältnisse. Erst im dritten Band kamen die Aspekte andere Kulturen und Entwicklung dazu. ${ }^{36}$ Und auch in den Texten zu diesen Themen schimmert der Aspekt der Ökologie durch, wie etwa in der oben erwähnten Beschreibung der EvB von 1977.

Unter dem Deckmantel der Ökologie und mit dem Segen von Small is beautiful hatte sich wiederum ein Kulturrelativismus eingeschlichen, der für Entwicklungsländer nicht die „gleichen“ Bedingungen forderte, sondern „angepasste“. ${ }^{37}$ $\mathrm{Zu}$ Beginn der 1970er-Jahre verstand die Bewegung unter einem alternativen Handel den Aufbau einer Alternative zu Nestlé und beispielsweise den Bezug von Ujamaa-Pulverkaffee aus Tansania. 1977 veränderte sich das Verständnis des Begriffs „alternativer Handel“: Ziel war jetzt die Abkopplung Tansanias, die Rückkehr zum Rohstoff und der Verzicht auf Industrialisierung. Die kurze Phase der ausschliesslichen Aufmerksamkeit der westlichen Aktivisten für die Entwicklungsländer war schnell vorüber. Ebenso schnell vorüber war die kurze Aufmerksamkeit für den Aspekt der Modernisierung und Industrialisierung der Dritten Welt. Die Alternativbewegung übertrug ihre Abneigung gegen die Indu-

35 A. Bänziger: Entwicklungsland Welt - Entwicklungsland Schweiz, 40.

36 Dezentrale: Alternativ-Katalog 3.

37 M. Black: Oxfam the First 50 Years, 68, Dezentrale: Alternativ-Katalog 3, 571. 
strie unreflektiert und uneingeschränkt auf die Entwicklungsländer, bevor die Industrialisierung in Afrika überhaupt hatte einsetzen können.

\subsection{Internationale Organisationen und Unternehmen als neues Feindbild}

Der Internationale Währungsfonds und die Weltbank waren 1944 auf der Konferenz von Bretton-Woods gegründet worden. Sie waren urkeynesianische Institutionen, zumal John Maynard Keynes der Konferenz persönlich beigewohnt und die Verhandlungen stark geprägt hatte. Die westlichen Staaten einigten sich auf fixe Wechselkurse mit einer Art Gold-Dollar-Bindung. Die Vorschläge neoliberaler Ökonomen, die sich für flexible Wechselkurse aussprachen, wurden nicht erhört. Der Internationale Währungsfonds sollte dieses System der fixen Wechselkurse überwachen. Die Weltbank sollte beim Wiederaufbau der Volkswirtschaften nach dem Zweiten Weltkrieg behilflich sein, wiederum nach dem keynesianischen System des deficit spending, um die Wirtschaft anzukurbeln..$^{38}$ Dieses System der Nachkriegszeit rief jedoch in den 1970er-Jahren, wie von neoliberalen Ökonomen vorausgesagt, eine Stagflation hervor: Die Volkswirtschaften der USA oder Grossbritanniens stagnierten, während sie gleichzeitig eine Inflation verzeichneten. Der US-Dollar, an den das Währungssystem von Bretton-Woods gekoppelt war, wurde somit immer billiger - zum Nachteil vieler anderer beteiligter Währungen. Dies führte bei mehreren Zentralbanken zur Aufgabe der Gold-DollarBindung und zum Zusammenbruch des - keynesianischen - Bretton-WoodsSystems. Die Folge war in zahlreichen Ländern und internationalen Organisationen Ende der 1970er-Jahre der Übergang zu neoliberalen Rezepten: Die „conservative counterrevolution“" war geboren. ${ }^{39}$

Als die westlichen Länder 1973 der Reihe nach ihre Wechselkurse freigaben und das Bretton-Woods-System zusammenbrach, schlug der neoliberale Ökonom Milton Friedman vor, sowohl den Internationalen Währungsfonds als auch die Weltbank einfach abzuschaffen. Die beiden Organisationen waren mit dem Zweck gegründet worden, das Bretton-Woods-System zu überwachen, und mit dem Zusammenbruch des Bretton-Woods-System hatten sowohl die Weltbank als auch der Internationale Währungsfonds den Zweck ihres Bestehens verloren. Den Grundsätzen der Politischen Ökonomie folgend, befürchtete Milton Friedman, die

38 Hauser, Heinz; Gedult von Jungenfeld, Martin: Die Schweiz und die Bretton-Woods-Institutionen (IMF und Weltbank), in: Richard Senti, Andreas R. Ziegler (Hg.): Die Schweiz und die internationalen Wirtschaftsorganisationen (Zürich 2005) 75-106.

39 J. Toye, R. Toye: UN and Global Political Economy, 254. 
Vertreter der beiden Institutionen würden sich neue Aufgabenbereiche suchen und ihren bürokratischen Apparat weiter ausbauen. ${ }^{40}$ Friedman sollte Recht behalten. Die beiden Institutionen wurden nicht abgeschafft und ihre Zielsetzung wurde tatsächlich neu geschrieben, zudem wuchsen sie weiterhin stetig. ${ }^{41} \mathrm{Nach}$ einer Übergangsphase wurde 1978 der neue Zweck in den Statuten festgeschrieben, nämlich die Förderung des Wirtschaftswachstums der Entwicklungsländer. ${ }^{42}$ Aus den supranationalen Organisationen, die ursprünglich die monetäre Stabilität und den Wiederaufbau Europas nach dem Zweiten Weltkrieg beaufsichtigt hatten, waren im Laufe der 1970er-Jahre Entwicklungsorganisationen geworden. Für die westlichen Staaten wie auch für die Dritte-Welt-Bewegung bedeutete dies, dass sie sich gegenüber den beiden Bretton-Woods-Institutionen neu positionieren mussten. Zudem verschrieben sich die beiden Institutionen ausgerechnet dann dem wirtschaftlichen Wachstum in Entwicklungsländern, als sich die Wachstumskritik in der öffentlichen Meinung der westlichen Gesellschaften durchsetzte.

Die OECD wiederum hatte die Entwicklung der Bretton-Woods-Institutionen vorweggenommen. Diese Vereinigung der Industrieländer entstand 1961 aus der OEEC (Organisation for European Economic Co-operation). Diese war 1949, ähnlich wie die Bretton-Woods-Institutionen, mit dem Zweck gegründet worden, den wirtschaftlichen Wiederaufbau Westeuropas und die Umsetzung des Marshall-Plans zu koordinieren. 1961 schien ihr Zweck erfüllt, doch sie wurde nicht einfach abgeschafft, sondern in eine Nachfolgeorganisation überführt, für die neue Aufgaben geschaffen wurden. So sollte die neue OECD ab 1961 auch eine Zusammenarbeit der Mitgliedstaaten in der Entwicklungspolitik beaufsichtigen. ${ }^{43}$

Die Neuorientierung der internationalen Organisationen nach 1973 ging einher mit einer weltweiten Wirtschaftskrise. Auch für die Schweiz, in der die Krise weniger ausgeprägt war als in anderen Industrienationen, bedeutete die Wirtschaftskrise von 1973 einen Mentalitätswechsel. Die Nachkriegszeit mit ihrem ungebremsten Wachstum und der Konjunkturüberhitzung war vorüber. Sie machte einer Epoche Platz, in der die Arbeitslosigkeit im Inland und die Sorge um das eigene Wirtschaftswachstum wieder prominent auf der Agenda standen. Die Gewerkschaften verzeichneten in der Schweiz in den 1960er-Jahren am meisten

40 Friedman, Milton; Friedman, Rose D.: Two Lucky People. Memoirs (Chicago 1998) 220.

41 Vaubel, Roland: Bureaucracy at the IMF and the World Bank: A Comparison of the Evidence, in: The World Economy 19/2 (1996) 195-210.

42 H. Hauser, M. Gedult von Jungenfeld: Schweiz und die Bretton-Woods-Institutionen.

43 Baldi, Marino; Beglinger, Lukas: Die Schweiz und die Organisation für wirtschaftliche Zusammenarbeit und Entwicklung (OECD), in: Richard Senti, Andreas R. Ziegler (Hg.): Die Schweiz und die internationalen Wirtschaftsorganisationen (Zürich 2005) 27-46, 29. 
Mitglieder und einen Höhepunkt ihres politischen Einflusses. ${ }^{44}$ Nach der Ölkrise von 1973 lebten sie noch ein letztes Mal zur Bedeutung der 1960er-Jahre auf.

Im Kontext dieser sehr starken Präsenz der Gewerkschaften im öffentlichen Leben der 1960er- und 70er-Jahre muss denn auch die Politik der EvB gesehen werden. 1968 waren es noch arrivierte Theologen, die von der Schweizer Wirtschaft und damit auch von den Arbeitnehmerinnen und -nehmern Einbussen forderten, und zwar auf die Gefahr hin, die Gewerkschaften vor den Kopf zu stossen. Die Passage in der „Erklärung von Bern“, in der eine Abfederung des Strukturwandels begrüsst wird (,für unsere Wirtschaft keine allzu jähen Erschütterungen resultieren“), dürfte denn auch eine Konzession an die Gewerkschaften gewesen sein. ${ }^{45}$ Unter den Erstunterzeichnern findet sich auch Jacques Vittori, Sekretär der Christlichen Gewerkschaft der Textilarbeiter. ${ }^{46}$ Vittori stellte somit bereits 1968 das Bindeglied zwischen der Dritte-Welt- und der Gewerkschaftsbewegung her. Diese Brücke, die er im Namen des Christentums schuf, sollte jedoch erst in der Wirtschaftskrise der ersten Hälfte der 1970er-Jahre zum Tragen kommen und sich später vor allem über personelle Verflechtungen noch verstärken. ${ }^{47}$

1968 war es der Dritte-Welt-Bewegung noch möglich gewesen, in Zeiten der Hochkonjunktur von den Bürgern und Bürgerinnen der Schweiz die Aufgabe von Privilegien zu fordern. Auch 1973 und 1974 - zur Zeit der ersten Ujamaa-Pulverkaffee-Aktionen der EvB - hallte das Vertrauen in die Schweizer Wirtschaft noch nach. Im Rahmen dieser Aktion forderten die Pulverkaffeeverkäufer sehr klar, dass die Schweizerinnen und Schweizer in Zukunft Industrieprodukte aus Entwicklungsländern kaufen sollten und somit bewusst nicht die Binnenwirtschaft unterstützen. Die Bereitschaft, eigene wirtschaftliche Privilegien zugunsten der Volkswirtschaften von Entwicklungsländern aufzugeben, ist die (christliche) Grundidee der „Erklärung von Bern“ von 1968. Diese Bereitschaft kann einerseits mit der christlichen Grundhaltung der Initianten erklärt werden. Andererseits ist die Bereitschaft, wirtschaftliche Privilegien abzugeben, auch bezeichnend für die Hochkonjunkturphase und das Wirtschaftswunder der Nachkriegszeit, als derartige Forderungen in der Bevölkerung überhaupt Anklang finden konnten. Bereits 1968, erst recht aber nach der Krise von 1973, sollte die Dritte-Welt-Bewegung jedoch die Rolle der inländischen Arbeiterinnen und Arbeiter - und somit die

44 Degen, Bernard: Gewerkschaften, in: Marco Jorio (Hg.): Historisches Lexikon der Schweiz (Basel 2002-2014) http://www.hls-dhs-dss.ch/textes/d/D16481.php (17.2. 2015).

45 Siehe Punkt 5 des Manifests. SozArch, EvB, Ar 430.25.1. EvB, Anfangszeit: Die Erklärung von Bern, März 1968.

46 SozArch, EvB, Ar 430.25.1. EvB, Anfangszeit: Die Erklärung von Bern, März 1968.

47 Siehe dazu Kapitel 4.4: Parlamentarier im Dienste der Erklärung von Bern. 
Gewerkschaftsanliegen - miteinbeziehen müssen, um überhaupt ein Publikum zu finden. ${ }^{48}$ Gerade die Kritik der Dritte-Welt-Bewegung an multinationalen Unternehmen entzündete sich nicht selten an der Entlassung eines bekannten Gewerkschaftsführers, der in einer Tochterfiliale eines Schweizer Unternehmens in einem Entwicklungsland tätig war, oder etwa an der Nichtbeachtung von Gewerkschaftsanliegen. Diese gewerkschaftliche Sicht sollte denn auch zur Gründung des Solifonds führen. ${ }^{49}$

1972 bis 1975 folgte die Welternährungskrise, auf welche die internationale Gemeinschaft jedoch anders reagierte als noch auf die Hungerkrisen der 1960erJahre. ${ }^{50}$ Insbesondere wurde auch auf offizieller Ebene, so etwa bei der EWG, Kritik an Food Aid laut, also an Nahrungsmittelhilfen aus der europäischen Überschussproduktion an arme Länder. Der Umweltschutz bzw. die „natürliche“, lokale und kleinbäuerliche Produktion der Nahrungsmittel wurde sowohl auf der formellen wie auf der informellen Ebene zum neuen Lösungsansatz. ${ }^{51} 1974$, genau ein Jahrzehnt nach der UNCTAD in Genf, auf der die Entwicklungsländer lautstark nach Handel gerufen hatten, hatte die Umweltproblematik auch die Entwicklungsländer eingeholt. Nachdem sich ein Scheitern des import substitution investment sowohl auf wirtschaftlicher wie auf politischer Ebene abzuzeichnen begann, eröffnete sich hier ein neuer Bereich. Die NGO-Bewegung sammelte sich auf der Konferenz der FAO in Rom. Verschiedene Aktivistinnen und Aktivisten sowie Vertreter von gerade erst gegründeten NGOs hatten sich zu einem alternativen Treffen neben der offiziellen Konferenz zusammengefunden und gaben eine alternative Konferenzzeitschrift heraus. ${ }^{52}$ Das Ziel der NGOs war eine alternative Berichterstattung für die Konferenzteilnehmerinnen und -teilnehmer, um den Agrarkonzernen nicht das Feld zu überlassen. ${ }^{53}$ Wie Kuhn bereits beobachtet hat, sind die Ursprünge der organisierten Alternativbegleitung internationaler Konferenzen durch NGOs bei dieser Parallelveranstaltung zur FAO von 1974 zu suchen. ${ }^{54}$

In den Jahren 1973 und 1974 erfolgte unter anderem als Folge der Ölkrise bzw. der hohen Benzinpreise ein explosiver Anstieg des Weltmarktpreises für Grund-

48 SozArch, EvB, Ar 430.10.2. Anne-Marie Holenstein, Ueberlegungen betr. Entwicklungspolitische Verfassungsinitiative, 16.4.1975.

49 B. Graf: Gewerkschaften und Dritte Welt. Siehe dazu auch Kapitel 4.3. Das Ende der Modernisierung: Allianz mit den Gewerkschaften, gegen Staudämme.

50 Siehe dazu C. Gerlach: Famine Responses.

51 Ebd., 930.

52 Bodleain Library, Oxford, Oxfam archive. MS.Oxfam PUB/528 - 9, PAN issues.

53 A.-M. Holenstein-Hasler, R. Renschler, R. H. Strahm: Entwicklung heisst Befreiung, 74.

54 K. J. Kuhn: Entwicklungspolitische Solidarität, 257-258. 
nahrungsmittel, der durch protektionistische Massnahmen noch verschärft wurde. Die Preise für Reis, Weizen und Mais stiegen um 100 bis 200 Prozent. ${ }^{55}$ In Kombination mit Dürre und politischer Instabilität führten die hohen Getreidepreise zu Hungerkatastrophen, beispielsweise in Äthiopien. Die Bilder der Hungerkatastrophe in Äthiopien haben die westliche Bevölkerung und die Entwicklung der Dritte-Welt-Bewegung nachhaltig geprägt. ${ }^{56}$ Bereits während der Welternährungskrise sahen Expertinnen und Experten, was die neuere Forschung der letzten Jahre bestätigt hat: Ein wichtiger Grund für die explosive Preissteigerung lag in der explosiven Preissteigerung des Erdöls aufgrund der OPEC-Krise (Organization of the Petroleum Exporting Countries, OPEC) sowie im erneuerten Protektionismus, den diese zur Folge hatte. ${ }^{57}$ Ebenfalls hatte der Agrarprotektionismus der Industrieländer bereits zu Beginn der 1970er-Jahre dazu geführt, dass Entwicklungsländer künstlich verbilligte Agrarprodukte aus den Industrieländern importierten und bei einer Preissteigerung die Zeche zahlten. In der Zeit der Welternährungskrise von 1972 bis 1975 verwandelte sich die EWG nun noch mehr als zuvor in eine Festung. ${ }^{58}$ So war sie zunächst auf ihre eigene Nahrungssicherheit bedacht und sprach ein Ausfuhrverbot für Getreide aus. Ebenfalls sicherte sie sich Getreideimporte aus den USA. ${ }^{59}$ In diesem Kontext lässt sich erklären, dass die FAO-Konferenz von 1974 zunächst das Ziel verfolgte, die EWG zu Food Aid zu verpflichten und sie nicht etwa davon abzuhalten.

Gerade der Erfolg der Idee Small is beautiful, welche die lokale Produktion für den Eigenbedarf forderte, muss in den Kontext der Welternährungskrise von damals gestellt werden. Die Schlussfolgerung, welche die Dritte-Welt-Bewegung aus der Welternährungskrise zog, bestand darin, dass sie die Bedeutung der lokalen Produktion erkannte. Der Fokus auf die lokale, traditionelle und kleinräumige Produktion war aber auch und insbesondere eine Kritik an der sogenannten grünen Revolution, deren negative Umweltbilanz in den 1970er-Jahren sichtbar wurde. Mit der grünen Revolution werden einerseits die Entwicklung und andererseits die Verbreitung von neu entwickeltem Saatgut, Pflanzenschutz- und Schädlingsbekämpfungsmittel bezeichnet. Ihre Anfänge liegen in den 1940erJahren; in den 60er-Jahren wurde insbesondere in Entwicklungsländern, etwa in Indien, mit grossangelegten Programmen die grüne Revolution implementiert.

55 Headey, Derek; Fan, Shenggen: Anatomy of a Crisis: the Causes and Consequences of Surging Food Prices, in: Agricultural Economics 39 (2008) 375-391.

56 Müller, Angela; Rauh, Felix (Hg.): Wahrnehmung und mediale Inszenierung von Hunger im 20. Jahrhundert (Basel 2014).

57 D. Headey, S. Fan: Anatomy of a Crisis.

58 C. Gerlach: Fortress Europe.

59 Ebd., 246. 
Diese führte auch tatsächlich zu bedeutenden Produktionssteigerungen. ${ }^{60}$ In den 1960er-Jahre wurden aber die negativen Folgen, etwa des Insektizids DDT, für Menschen, Tiere und für die Pflanzenvielfalt ersichtlich. ${ }^{61}$ Gleichzeitig zeigte sich, dass in den Industrieländern eine massive Überproduktion von Agrarprodukten bestand und dass diese Länder der Ersten Welt im Namen der Hungerbekämpfung ihre überschüssige Agrarproduktion in den Entwicklungsländern abluden, dort die lokale Produktion unterminierten und Abhängigkeit kreierten. Kritisiert wurde ferner, dass Bauern in Entwicklungsländern von Saatgut- und Pestizidproduzenten abhängig wurden, kurz: Die westlichen Agrokonzerne wurden von der Dritte-Welt-Bewegung kritisiert. ${ }^{62}$ Mit den multinationalen Agrarkonzernen erwuchs der Fair-Trade-Bewegung somit ein neues Feindbild, das sich nahtlos in die ursprünglich marxistisch-leninistische Imperialismustheorie einfügte.

Das Zusteuern der Dritte-Welt-Bewegung auf das Thema Landwirtschaft und weiter auf die weltweite, lokale, ökologische und von Kleinbauern betriebene Landwirtschaft spiegelt sich somit in den Entwicklungen und Ereignissen auf internationaler Ebene. Die NGOs, die sich unterdessen professioneller organisiert hatten, reagierten einerseits auf die Welternährungskrise, andererseits auf die supranationalen Organisationen und deren Politik, die sich in der FAO-Konferenz manifestierte. War 1964 und 1968 noch die jeweilige UNCTAD-Konferenz im Zentrum der Diskussion der Dritte-Welt-Bewegung gestanden, war es 1974 die technokratische FAO und deren Unterwanderung durch nationale Regierungen und Agrobusiness-Konzerne. Einerseits wird hier ersichtlich, wie das Thema Landwirtschaft und Ökologie das Thema Marktzugang und Industrialisierung abgelöst hat. Andererseits wird deutlich, dass die aktive und fordernde Rolle der Entwicklungsländer, mit der sie 1964 und 1968 an den UNCTAD-Konferenzen sehr viel Hoffnung auf Entwicklung geweckt hatten, bereits nach einem Jahrzehnt der Vergangenheit angehörte. Anstelle einer von den Entwicklungsländern selbst anberaumten Konferenz, auf der sie ihre Forderungen präsentierten und damit die Dritte-Welt-Bewegung im Westen erst inspirierten, nahmen nun mit der FAOKonferenz die supranationalen Organisationen überhand - die im Übrigen unterdessen ein bürokratisches Eigenleben entwickelt hatten. Die im Nachgang dazu entstandenen neuen NGOs im Westen hatten unterdessen genauso ihr organisationales Eigenleben entwickelt. Marktzugang und die Industrialisierung und da-

60 Evenson, R. E.; Gollin, D.: Assessing the Impact of the Green Revolution, 1960 to 2000, in: Science 300/5620 (2003) $758-762$.

61 Carson, Rachel: Silent Spring (Boston 1962).

62 Dazu insbesondere Lappé, Frances Moore; Fowler, Cary; Collins, Joseph: Food First. Beyond the Myth of Scarcity (Houghton 1977) und George, Susan: How the Other Half Dies. The Real Reasons for World Hunger (Harmondsworth 1976). 
mit die im Rahmen der internationalen Organisationen weiterhin vorgebrachten Anliegen der Entwicklungsländer selbst waren nun nicht mehr im Fokus ihrer Arbeit.

\subsection{Der implizite Konsens zur Ablehnung von Privatinvestitionen in Entwicklungsländern}

Die marxistisch-leninistische Theorie des wirtschaftlichen Nord-Süd-Imperialismus der 1960er-Jahre nahm weiterhin Bezug auf den klassischen Marxismus des 19. Jahrhunderts. Das Bild des Kapitalisten als Ausbeuter blieb demnach von den paläoliberalen Zeiten des Pauperismus bis in die Zeiten des Wohlfahrtsstaats in der zweiten Hälfte des 20. Jahrhunderts bestehen. ${ }^{63}$ In den 1950er- und 60erJahren befolgte die offizielle Schweiz das Credo, dass unternehmerische Investitionen in Entwicklungsländern mit Entwicklungshilfe gleichzusetzen seien. Unter dieser Prämisse war etwa die Einführung der Exportrisikogarantie für Schweizer Firmen 1958 vonstattengegangen. Sie wurde als Beitrag zur Entwicklungshilfe angesehen. ${ }^{64}$ Nachdem zahlreiche Skandale aufgedeckt worden waren, darunter auch prominent die Publikation der „Multi-Papers“ durch die EvB im Jahr 1978, entstanden jedoch auch ausserhalb des kleinen Kreises der Dritte-Welt-Bewegung Zweifel am Konzept der Privatinvestition als Entwicklungshilfe. ${ }^{65}$ Studien über die ökologischen Folgen der Modernisierung sowie über die Aufwertung der traditionellen Kulturen im Rahmen des Konzepts Small is beautiful verstärkten diese Zweifel. So etablierte sich in den 1970er-Jahren ein Konsens unter der sehr breiten alternativen und der bürgerlich-kirchlichen Bewegung, dass Privatinvestitionen in Entwicklungsländern abzulehnen seien. ${ }^{66}$ Diese Ablehnung zehrte einerseits vom Ansatz der Abkopplung und dem Ansatz der arbeitsintensiven Industrialisierung. ${ }^{67}$ Dazu kamen andererseits neue Studien über die Auswirkungen, die Grossinvestitionen in den 1960er-Jahren in den Entwicklungsländern auf Kultur, Kleingewerbe und Umwelt gehabt hatten. ${ }^{68}$ Diese neuen Erkenntnisse und Men-

63 P. Collier: The Bottom Billion, 157-159. Siehe zur Bildsprache des Kapitalisten als „fettem Schwein“ auch etwa K. J. Kuhn: Entwicklungspolitische Solidarität, 261.

64 Siehe dazu in der Systematischen Rechtssammlung des Bundes das Bundesgesetz über die Exportrisikogarantie vom 26. September 1958, aufgehoben 2007 (https://www.admin.ch/opc/de/ classified-compilation/19580168/) (8.1.2018).

65 Erklärung von Bern, Vereinigung für Solidarische Entwicklung: Die ,Multi-Papers‘.

66 Siehe beispielsweise A. Bänziger: Entwicklungsland Welt - Entwicklungsland Schweiz, 41.

67 G. Austin: The Developmental State.

68 F. M. Lappé, C. Fowler, J. Collins: Food First. 
talitäten paarten sich jedoch mit dem sehr viel älteren christlichen Misstrauen gegenüber der Figur des Kaufmanns. 1975, im Vorfeld der Ausarbeitung des eidgenössischen Gesetzes über die Entwicklungshilfe, gab eine sehr breite Koalition der Hilfswerke und der EvB das Buch „Entwicklungsland Welt - Entwicklungsland Schweiz“ heraus, das, ähnlich wie die „Alternativkataloge“, die Grundhaltung der Dritte-Welt-Bewegung ausdrückte. ${ }^{69}$ Die Privatinvestitionen bilden einen zentralen Teil der Publikation. Ein ausführliches Kapitel unter diesem Titel zeigt über vier Seiten die Haltung der Dritte-Welt-Bewegung auf. So steht da etwa:

\begin{abstract}
Die Konzernniederlassungen in Entwicklungsländern fördern die Auseinanderentwicklung zwischen modernen Zentren und unterentwickelten Peripherien innerhalb der Entwicklungsländer. Mit ihrer Präsenz und ihren Aktivitäten führen sie westliche Wertvorstellungen, Konsumgewohnheiten und Verhaltensweisen ein. Konzerne gewisser Branchen investieren heute in Entwicklungsländern, um die strengen und kostenverursachenden Umweltschutzbestimmungen zu umgehen. Nicht selten versuchen multinationale Konzerne die am herrschenden Zustand interessierten einheimischen Eliten einzubeziehen oder zu beteiligen. Joint Ventures, also Betriebe mit gemeinsamer Beteiligung von multinationalen Konzernen einerseits und Staat oder Privaten aus dem Entwicklungsland andererseits sind in diesem Licht problematisch. ${ }^{70}$
\end{abstract}

Mit ihrer grundsätzlichen Ablehnung von Privatinvestitionen und der Forderung nach strengen Kriterien, die auf eine Verhinderung abzielten, haben die Entwicklungsorganisationen den Kurs der kommenden Jahrzehnte vorgespurt. Irgendwann sollte diese grundsätzliche Ablehnung von Investitionen in den Alltagsgebrauch übergehen und die Notwendigkeit wegfallen, ausdrücklich darauf hinzuweisen, wie es noch 1975 geschah. Diese ausdrückliche Negierung der privaten Auslanddirektinvestitionen ging 1975 noch einher mit einer zumindest halbherzigen Unterstützung des import substitution investment sowie der $\mathrm{Ab}$ kopplung, also mit Konzepten, die den Aufbau einer arbeitsintensiven eigenen Industrie - angepasst an die lokalen Gegebenheiten - in den Entwicklungsländern vorsahen. Als diese Option Ende der 1970er-Jahre im Rahmen der Überschuldung der Entwicklungsländer, des wirtschaftlichen Scheiterns des import substitution investment und der Politikänderung des Internationalen Währungsfonds und der Weltbank wegfiel, blieb bei der Dritte-Welt-Bewegung im Westen die Ablehnung von westlichen Auslanddirektinvestitionen bestehen. Gleichzeitig wurden jedoch keine neuen Alternativen zur Modernisierung vorgebracht. Die Modernisierung der Entwicklungsländer fiel somit als konzeptuelle Leitlinie Ende der 1970er-Jahre vom Tisch. Das Konzept des Fair Trade, das in Entwicklungs-

69 A. Bänziger: Entwicklungsland Welt - Entwicklungsland Schweiz.

70 Ebd., 41-42. 
ländern einzig Rohstoff produzierende Kleinbauern vorsah, füllte in den 1980erJahren die Lücke. Die Ablehnung von Privatinvestitionen musste von da an nicht mehr formuliert werden, sondern war in den öffentlichen Mainstream eingeflossen und zu einer Selbstverständlichkeit geworden. In dieser Selbstverständlichkeit fand sich die Alternativbewegung unbeabsichtigt in einer Allianz mit den Neokonservativen, die mit den Sozialisten eine Abneigung gegen Grosskonzerne teilten. Der Grundsatz des Primats des Kleingewerbes und die Abneigung von Moderne, Werbung und Massenproduktion bildete eine starke Schnittmenge zwischen der Alternativbewegung und den Neokonservativen. Die moralische Überhöhung der Landwirtschaft, der Bauernfamilien und des Kleingewerbes ist ein sehr wichtiger Teil der neokonservativen Theorie und ergänzte sich mit der Abneigung gegen Grosskonzerne.

Der deutsche Ökonom Wilhelm Röpke (1899-1966), ein wichtiger Vordenker der neokonservativen Bewegung, betrachtete Bauern- und Gewerblerfamilien als die tragenden Elemente der Gesellschaft. Röpke, der in der Schweiz lebte und publizierte, lehrte von 1937 bis zu seinem Tod am Institut für Internationale Beziehungen in Genf und war einer der führenden frühen Neoliberalen und AntiKeynesianer. ${ }^{71}$ Er ging als einer der wenigen Neoliberalen der 1940er- und 50erJahre aber weiter und gestand dem Staat auch zu, die Landwirtschaft handelspolitisch zu schützen und notfalls mit Subventionen zu unterstützen. ${ }^{72}$ Für Röpke, der in seinem Spätwerk immer stärker zum Neokonservatismus tendierte, war der bäuerliche Familienbetrieb der unabdingbare Kern einer gesunden, lebensfähigen Gesellschaft:

Es ist nicht so sehr die Erzeugung der Nahrungsmittel und Rohstoffe als solche, die uns hier interessiert, wie jene besondere Form der Erzeugung, die wir die bäuerliche nennen, denn nur diese besitzt die unschätzbare soziologische Bedeutung, von der wir ausgehen, und nur an diese denken wir, wenn wir die Landwirtschaft als den letzten mächtigen Zufluchtsort gegenüber der Vermassung, Mechanisierung und Verstädterung unserer Zeit empfinden und ihren Verfall als ,Landflucht‘ beklagen. ${ }^{73}$.

Dies schrieb Röpke bereits 1942, als die Schweiz in einer Anbauschlacht gemäss dem Plan Wahlen die landwirtschaftliche Produktion möglichst maximierte. Röpke nahm die kulturelle Bedeutung des Bauerntums und das bäuerliche Leben als „mächtige[n] Zufluchtsort“ für die wohlstandsmüde westeuropäische Gesellschaft der 1980er-Jahre vorweg. Daher plädierte er dafür, die Landwirtschaft nicht

71 Siehe insbesondere J. Solchany: Wilhelm Röpke.

72 P. Plickert: Wandlungen des Neoliberalismus, 235-239.

73 W. Röpke: Die Gesellschaftskrisis, 316. 
als „Industrie wie jede andere“ $\mathrm{zu}$ sehen und nicht die klassischen marktwirtschaftlichen Gesetze walten zu lassen:

Gewiss bildet die Landwirtschaft einen Sektor der Volkswirtschaftslehre, auf den die Prinzipien der freien Marktwirtschaft immer nur mit starken Vorbehalten anwendbar gewesen sind, und gewiss haben die besonderen Verhältnisse, die hier herrschen, von jeher die Wirtschaftspolitik vor Sonderprobleme gestellt, deren Lösung nicht dem freien Spiel der Kräfte überlassen werden konnte. ${ }^{74}$

Gerade um die Agrarpolitik wurde jedoch innerhalb der Mont Pèlerin Society und somit im Heizkessel der frühen neoliberalen Bewegung heftig gestritten. ${ }^{75}$ Röpke lud 1957 den neokonservativen amerikanischen Literaturwissenschaftler Russell Kirk in die Schweiz ein. Auf dem Jahrestreffen der Mont Pèlerin Society in St. Moritz wurde Kirk als Redner geführt. ${ }^{76}$ Dies provozierte Friedrich August von Hayek zu der Rede mit dem Titel „Why I am not a conservative“ ${ }^{77}$ Diese markierte die Spaltung der Bewegung in eine neoliberale und eine neokonservative Richtung. In seiner Rede unterteilte Hayek Liberale und Konservative aufgrund ihrer Haltung zur Landwirtschaft:

Conservatives usually oppose collectivist and directivist measures in the industrial field, and here the liberals will often find allies in them. But at the same time, conservatives are usually protectionists and have frequently supported socialist measures in agriculture. ${ }^{78}$

Röpke hatte sich mit seiner Unterstützung der Landwirtschaft und der Einladung Kirks innerhalb der neoliberalen Bewegung ins (neo-)konservative Abseits manövriert. Dies betraf auch seine zahlreichen Anhängerinnen und Anhänger in der Schweiz. Hier hatte Röpke extensiv insbesondere in der NZZ publiziert und zahlreiche Ökonomen ausgebildet oder beeinflusst, die nun bedeutende Positionen in Politik, Wirtschaft und Gesellschaft einnahmen. Auch nach Röpkes Austritt aus der Mont Pèlerin Gesellschaft 1962 und seinem frühen Tod 1966 sollten sie seine Gesinnung weitertragen. ${ }^{79}$

Wie Solchany in seiner minutiös recherchierten Biografie Röpkes aufzeigt, war der Deutsche Gelehrte ein wichtiger Pfeiler der Geistigen Landesverteidigung in der Schweiz. ${ }^{80}$ Seine Bücher, Zeitungsartikel und Vorträge trugen massgeblich

74 Ebd., 321-322.

75 P. Plickert: Wandlungen des Neoliberalismus, 235-239.

76 Ebd., 309

77 F. A. v. Hayek: Constitution of Liberty, 397-411.

78 Ebd., 403.

79 A. Franc: Wie der Vorort.

80 J. Solchany: Wilhelm Röpke. Siehe auch H. U. Jost: Politik und Wirtschaft, 196-197. 
dazu bei, die nationale Identität der Schweiz als Nation der Bauern und Gewerbler zu untermauern. Gerade in Kreisen des Zürcher Freisinns wurde Röpke richtiggehend verehrt. Interessant ist wiederum, welche Aspekte die Zürcher Freisinnigen aus Röpkes Monumentalwerk herausgriffen und im nationalen Diskurs perpetuierten. So schrieb etwa NZZ-Wirtschaftsredaktor Carlo Mötteli in seiner Rezension von Röpkes „Gesellschaftskrisis der Gegenwart“ 1942:

Dezentralisierung, natürliche Förderung der kleineren Produktions- und Siedlungseinheiten und der soziologisch gesunden Lebens- und Berufsformen (obenan der bäuerlichen und handwerklichen), Rückführung aller Dimensionen und Verhältnisse auf menschliche Masse (,à la taille de l'homme', nach dem treffenden Ausdruck von Ramuz). ${ }^{81}$

Nicht nur in der Schweiz, sondern auch auf internationaler Ebene hat diese Passage in Röpkes Werk Aufmerksamkeit erregt. So wird sie denn auch im Vorwort der englischen Ausgabe zitiert: „Humanizing of economic strucutre, à la taille de l'homme in the phrase of Ramuz, was the kernel of Roepke's proposals. " 82 Die Forderung nach Kleinheit, nach „menschlichem Mass“ war die Hauptbotschaft, die aus Röpkes Werk in der Bevölkerung erfasst wurde. Damit schloss Schumachers „Small is Beautiful“, das in der Deutschen Übersetzung den Untertitel „Die Rückkehr zum menschlichen Mass“ trug, an eine bereits bestehende Geisteshaltung an. ${ }^{83}$ Erklärend ist in diesem Kontext ein weiterer Begriff, der neben dem „menschlichen Mass“ eine Schnittmenge zwischen den Neokonservativen, den Neoliberalen und dem linksgrünen Dritte-Welt-Lager markiert: der Dezentralismus. Die Grundvoraussetzung nicht nur für Totalitarismus, sondern auch für den interventionistischen Keynesianismus ist ein Zentralstaat, der lenkt, leitet und eingreift, anstatt Marktkräfte walten zu lassen. Das Misstrauen gegenüber dem Staat, das frühe Neoliberale hatten, die wie Wilhelm Röpke vor den Missbräuchen eines überbordenden Zentralstaates geflohen waren, sass tief. Nebst der bäuerlichen Kultur hob Röpke insbesondere auch den Föderalismus und das dezentralisierte politische System der Schweiz aufs Podest. Ein dominierender Zentralstaat wurde von den Neoliberalen und den Neokonservativen seit den 1930erJahren klar abgelehnt. Während neoliberale Ökonomen vom freien Spiel der Marktkräfte sprachen, priesen die Neokonservativen und die Nicht-Ökonomen fast wortwörtlich wie in der linksgrünen Bewegung der 1970er-Jahre kleinräumige Strukturen nicht als ökonomisch, sondern moralisch überlegen. So fasste etwa

81 Carlo Mötteli, Der „Dritte Weg“, NZZ, 17.5.1942.

82 Röpke, Wilhelm: The Social Crisis of our Time (New Brunswick (N.J.) 1992) xi.

83 E. F. Schumacher: Small is Beautiful. 
der US-amerikanische Literaturwissenschaftler Russel Kirk Röpkes Ansatz in Worten zusammen, die fast identisch bei E.F. Schumacher zu finden sind:

Family farms, farmers' cooperatives for marketing, encouragement of artisans and small traders, the technical and adminstrative possiblities of industrial decentralization, the diminution of the average size of factories, control of competition and restraint of monopolies, the graduate substitution for the 'old-style welfare policy' of an intelligent trend toward selfsufficiency $^{84}$

„Decentralization“, „Self-sufficiency“, „farmers’ cooperatives“: Die Überschneidung zwischen der neokonservativen Ideologie und der Fair-Trade-Bewegung der späten 1970er-Jahre ist nicht von der Hand zu weisen. So basiert und verweist das von der EvB vertriebene Buch „Zerstörung durch Überfluss“ auf Schumachers „Es geht auch anders“, in dem Schumacher inhaltlich mit Kirk und Röpke übereinstimmt:

Wir brauchen:

1. Eine Wiederherstellung echt schöpferischer Arbeit durch Entwicklung einer vereinfachten, vermenschlichten Technik

2. Eine radikal vereinfachte Lebensweise

3. Die Anerkennung des Vorrangs des Biologischen

4. Die Entwicklung einer dezentralisierten Wirtschaftsstruktur mit vorwiegend kleinen Betrieben

5. Die weitgehende Selbstversorgung kleiner, kohärenter Gruppen..$^{85}$

Der amerikanische Intellektuelle Theodore Roszak wies in seinem Vorwort zu einer amerikanischen Ausgabe von „Small is Beautiful“ auf diese ideellen Gemeinsamkeiten hin bzw. interpretierte er Schumachers „Dezentralismus“ als Erbe der libertär-anarchistischen Tradition der Wirtschaftswissenschaften:

Schumacher's work belongs to that subterranean tradition of organic and decentralist economics [...]. It is the tradition we might call anarchism, if we mean by that much abused word a libertarian political economy that distinguishes itself from orthodox socialism and capitalism by insisting that the scale of organization must be treated as an independent and primary problem. ${ }^{86}$

84 W. Röpke: The Social Crisis, xi.

85 E. F. Schumacher: Es geht auch anders, 49.

86 Schumacher, Ernst Friedrich: Small is Beautiful. Economics as if people mattered (New York 1975), 4. 
Schumachers Werk kann in verschiedene Traditionen eingeordnet werden. Das Zitat Russel Kirks weiter oben, das wie ein Ausschnitt aus den Alternativkatalogen der Dezentrale tönt, zeigt auf, wie die im Entstehen begriffene neokonservative Bewegung bereits in den frühen 1940er-Jahren die Dezentralisierung, den Kleinbauern und Handwerker sowie dessen traditionelle Produktionsmethoden und das Landleben zum Mass aller Dinge erhoben hatte. Gerade in der Schweiz war diese neokonservative Denkschule mit Wilhelm Röpke und seinem Umfeld stark verankert und portierte den Dezentralismus lange bevor Schumacher zu Beginn der 1970er-Jahre auf Studierende in Zürich traf. ${ }^{87}$ Hier präsentierte die linksgrüne Bewegung alten Wein des vermeintlichen Gegners in neuen Schläuchen, als sie ein Herausgeberkollektiv „Dezentrale“ nannte. ${ }^{88}$ Als die Umweltbewegung in den 1970er-Jahren dieselben Werte in ihr Programm aufnahm, war der Boden für einen breiten nationalen Konsens in der Schweiz also schon seit der Geistigen Landesverteidigung geebnet. Nicht nur der Westschweizer Schriftsteller C. F. Ramuz, bei dem Röpke den Begriff ,à la taille d'homme“ gelesen hatte, vor allem der Berner Autor Jeremias Gotthelf lieferte den Zürcher Bürgerlichen in den kommenden Jahrzehnten die kulturelle Unterfütterung, die ihr Bild der bäuerlichen Schweiz prägen sollte. ${ }^{89}$ So zitierte etwa Gerhard Winterberger 1965 in einem Artikel über die „Umstrittene Agrarpolitik im Industriestaat“ Gotthelf, der den Bauern „Handlanger Gottes“ nannte. ${ }^{90}$

Die Neokonservativen bliesen aber auch ins Horn der Multikritiker und hoben die kleinen und mittleren Unternehmen auf einen moralischen Sockel. In der Kritik der Grosskonzerne fanden sich somit linke, grüne und neokonservative Gruppen in den 1970ern zu einem impliziten Konsens zusammen. Wie oben erwähnt, übernahm auch die supranationale Entwicklungshilfe langfristig die Ansätze dieses Konsenses und machte trotz des neoliberalen Washington Consensus die Förderung kleiner und mittlerer Unternehmen zu einer Priorität. Dies basierte zwangsläufig auf moralischen Überlegungen, war doch die Wirksamkeit dieser Förderung von Kleinunternehmen in der Armutsbekämpfung als auch die

87 J. Solchany: Wilhelm Röpke, 43-45, U. Eichenberger: Ökologie und Selbstbestimmung, 25. 88 Dezentrale: Alternativ-Katalog 3.

89 Francillon, Roger: Ramuz, Charles Ferdinand, in: Marco Jorio (Hg.): Historisches Lexikon der Schweiz (Basel 2002-2014) http://www.hls-dhs-dss.ch/textes/d/D16054.php (16.12.2011), Holl, Hanns Peter: Gotthelf, Jeremias, in: Marco Jorio (Hg.): Historisches Lexikon der Schweiz (Basel 2002-2014) http://www.hls-dhs-dss.ch/textes/d/D11835.php (17.9.2010).

90 Winterberger, Gerhard: Umstrittene Agrarpolitik im Industriestaat, in: Schweizer Monatshefte 45/6 (1965) 516-532, 517. 
überlegene wirtschaftliche Leistung von kleinen und mittleren Unternehmen gegenüber Grosskonzernen empirisch nicht belegbar. ${ }^{91}$

Die stark neokonservative und röpkesche Prägung der Schweizer Bürgerlichen machte sich einerseits im bürgerlichen Lager der kirchlichen Dritte-WeltBewegung bemerkbar, andererseits auch im bürgerlichen Lager im Umfeld des Dachverbands der Schweizer Privatwirtschaft, des Vororts, und der FreisinnigDemokratischen Partei der Schweiz, welche das bürgerliche Lager bis in die 1990er-Jahre dominierte. Dem Vorort stand von 1970 bis 1987 der Berner Ökonom Gerhard Winterberger vor. ${ }^{92}$ Dieser hatte bei Röpke in Genf studiert, verehrte Röpke und blieb ihm bis zu dessen Tod eng verbunden. Seine Briefe an Röpke unterschrieb er mit „Ihr Hirtenknabe“, womit er auf seine Herkunft als Enkel eines Bergbauern im Haslital anspielte. ${ }^{93}$ Bereits in den 1950er-Jahren begann Winterberger in den Schweizer Medien über die Landwirtschaft und die kulturelle Bedeutung der Bergbauern zu publizieren. Er übernahm sozusagen von Röpke das Zepter und prägte in den 1960er-, 70er- und 80er-Jahren die bürgerliche Haltung zur Landwirtschaft. Dabei interpretierte er seine Funktion als Vorortsdirektor sehr frei, indem er sich in seinem Einsatz für den Schutz der Schweizer Landwirtschaft auch gegen die Interessen der vom Vorort vertretenen Unternehmen stellte. ${ }^{94}$ Insbesondere wird hier sichtbar, wie die „Hinterbänkler“ in der Mont Pèlerin Society, der Winterberger ebenfalls angehörte, in der Praxis die Vorgaben der neoliberalen Aushängeschilder der gelehrten Gesellschaft keineswegs umsetzten. In Winterbergers Schriften ist die bürgerliche Seite im impliziten Konsens zwischen den linksgrünen und den nationalkonservativen Bevölkerungsteilen in der Schweiz klar erkennbar. Nicht nur verteidigte Winterberger immer wieder die Figur des Bauern und Bergbauern und stilisierte diese und ihren ,geistigen Habitus“ zur nationalen Identifikationsfigur. ${ }^{95}$ Vielmehr nahm er auch die ablehnende Haltung der nationalkonservativen Bewegung zum Beitritt der Schweiz zu europäischen Institutionen vorweg, die von der linksgrünen bzw. der Dritte-WeltBewegung ebenfalls bereits ab 1970 geteilt wurde. So zeichnete Winterberger etwa in einem historischen Überblick das Bild der Schweiz als Nation der freien Bau-

91 Easterly, William Russell: The White Man's Burden. Why the West's Efforts to Aid the Rest have done So Much Ill and So Little Good (Oxford 2006) 55.

92 A. Franc: Wie der Vorort.

93 Institut für Wirtschaftspolitik, Universität Köln, Nachlass Wilhelm Röpke, Winterberger an Röpke, 20.5.1957.

94 A. Franc: Wie der Vorort.

95 Winterberger, Gerhard: Politik und Wirtschaft. Ausgewählte Reden und Aufsätze (Bern 1980). 
ern, die im Ancien Régime an den europäischen Höfen als „Tölpel“ verlacht, aber um ihre Freiheit beneidet wurden. ${ }^{96}$

Gerhard Winterberger steht repräsentativ für die bürgerliche Generation der Nachkriegszeit, welche die Geistige Landesverteidigung in die Schweizer Wachstums- und Wohlstandsgesellschaft überführte. Verankert in einem festen Stolz auf die kleine, bäuerliche Eidgenossenschaft konstituierte sich in der Schweiz eine neokonservative Bewegung, die zwar nicht der freien Markwirtschaft, sehr wohl aber multinationalen Grosskonzernen, der Massenproduktion und der Europäisierung ablehnend gegenüberstand. Die nationalsozialistische Ideologie hatte in der ersten Hälfte des 20. Jahrhunderts über den Weg des Antisemitismus wiederum das Amoralische des wirtschaftlichen Erfolgs betont. ${ }^{97}$ Restposten dieses Antisemitismus lebten in ganz Westeuropa auch nach Kriegsende in Form von Ressentiments gegen unüberschaubare und verschwiegene Grosskonzernen weiter. Die moralische Verwerflichkeit der Geldwirtschaft und des Grosskapitalisten in der westlichen Mentalität wird am besten in der Literatur ersichtlich. Der amerikanische Ideenhistoriker Irving Kristol hat die Rolle des Kaufmanns und später der Manager in Grosskonzernen in der Weltliteratur beobachtet. Er kommt zu dem Schluss, dass der „Kaufmann“ erst in der Nachkriegszeit zum wirklichen Stereotyp des Bösewichts wird:

Though the businessman per se has never been a fictional hero of bourgois society (as Stendhal observed, a merchant may be honorable but there is nothing heroic about him), it is only after the rise of 'big business' that the businessman becomes the natural and predistined villain of the novel, the drama, the cinema, and, more recently, television. ${ }^{98}$

Die sehr starke und breite Abneigung in der Bevölkerung gegen Grosskonzerne führte aber zu wichtigen empirischen Forschungen über die Rolle multinationaler Konzerne in Entwicklungsländern. Eine bahnbrechende Forschung stammt von Charles Kindleberger, der 1969 den Klassiker „American Business Abroad“ publizierte, in dem er auch auf den marxistisch-leninistischen Vorwurf des Neoimperialismus durch Direktinvestitionen multinationaler Firmen antwortete. ${ }^{99}$ Es folgte ein Jahr später Mira Wilkins mit „The Emergence of Multinational Enter-

96 G. Winterberger: Schweizerische Eigenart.

97 Muller, Jerry Zucker: Capitalism and the Jews (Princeton, N.J. 2010).

98 Kristol, Irving: Neoconservatism. The Autobiography of an Idea (New York 1995), 214-215.

99 Kindleberger, Charles Poor: American Business Abroad. Six Lectures on Direct Investment (New Haven 1969). 
prise“. ${ }^{100}$ Diesen empirischen Studien stand allerdings weiterhin die aus den 1960er-Jahren stammende theoretische Kritik an Grosskonzernen gegenüber, wonach Letztere nur Rohstoffe abschöpften, nicht investierten im Süden und an der Dependenz des Südens mitschuldig seien. Mit schwang die marxistisch-leninistische Theorie, dass multinationale Grosskonzerne verlängerte Arme des Imperialismus bzw. des Kapitalismus der Nationalstaaten seien. Diese theoretische, etwa auf Galtung und Senghaas basierende Kritik nahm Mitte der 1970erJahre in der schweizerischen Dritte-Welt-Bewegung überhand und beendete die modernisierungsfreundliche Phase der Zeit nach der ersten UNCTAD von 1964. ${ }^{101}$

Was die Bewegung schuldig blieb - und hier standen die NGOs und die akademische Ökonomie an einem Scheideweg -, war eine Antwort auf die sich gegen Ende dieser modernisierungsfreundlichen Phase stellenden Fragen. Denn etwa Mitte der 1970er-Jahre zeigte sich: Nach dem Scheitern des import substitution investment und nachdem man zur Erkenntnis gelangt war, dass es die Umwelt $\mathrm{zu}$ schützen galt und dass eine unbegrenzte Industrialisierung nicht wünschenswert war, präsentierte die Dritte-Welt-Bewegung keinen neuen Lösungsansatz, der erklärt hätte, wie denn der sich öffnenden Wohlstandsschere zwischen armen und reichen Ländern sonst zu begegnen wäre. Während das import substitution investment nicht mehr propagiert wurde, wurden private Auslanddirektinvestitionen kritisiert und abgelehnt mit den oben angegebenen Begründungen. Wie sollten die Volkswirtschaften im Süden nun die Armut bekämpfen? Sie sollten nicht mehr modernisieren, nicht mehr staatlich in Wirtschaft investieren und westliche Grosskonzerne sollten dort auch nicht mehr investieren. Dieser Konzeptwechsel, der Mitte der 1970er-Jahre vonstatten ging, zeigte sich unter anderem in den Publikationen von Pierre Bungener, der Mitte der 1960erJahre das Institut africain der Universität Genf aufgebaut hatte, aus dem später das IUED werden sollte. Die Prämisse der Gleichheit wurde verworfen und wiederum die „pluralité des mondes“ ausgerufen, im Vergleich zur Kolonialzeit jedoch mit umgekehrten Vorzeichen. ${ }^{102}$ Anstatt wie früher anzunehmen, dass die Menschen im Süden sich aus Minderwertigkeit nicht für eine Modernisierung eigneten, nahmen die westlichen Dritte-Welt-Aktivisten nun neu eine Art Gleichwertigkeit bzw. „Pluralität“ der Lebensstile an, die den Status quo, und somit faktisch die Armut, aufwertete und eine vermeintliche Gleichwertigkeit schuf. Dies war eine sehr elegante Lösung von zwei Problemen gleichzeitig,

100 Wilkins, Mira: The Emergence of Multinational Enterprise. American Business Abroad from the Colonial Era to 1914 (Cambridge, Mass 1970).

101 M. Schär: Strukturveränderungen statt Entwicklungshilfe, 33-38.

102 Bungener, Pierre; Grinevald, Jacques (Hg.): La pluralité des mondes. Théories et pratiques du développement (Genf 1975). 
nämlich dem Scheitern des import substitution investment und der Umweltproblematik. Zudem löste es auch noch ein drittes Problem, das Mitte der 1970erJahre im Rahmen der Wirtschaftskrise wieder aktuell wurde: Solange multinationale Konzerne nicht in Billigländer investierten, blieben die Arbeitsplätze im Inland. Die Multikritik, der „anticorporatism“, erlaubte es den Dritte-Welt-NGOs, mit den Gewerkschaften im Inland zusammenzuspannen. ${ }^{103}$ Die Kritik am Abbau von Arbeitsplätzen im Norden, an der Umweltverschmutzung, an der Ausbeutung der Arbeiter sowie dem Gewinnabzug ins Ausland ergänzten sich ideal zur Legitimierung des Neoprotektionismus der 1970er- und 80er-Jahre.

\subsection{Von der Dritten Welt zur Umwelt: die Neuausrichtung der Theologen der Anfangsjahre}

André Biéler, der mit „Gottes Gebot und der Hunger der Welt“ 1966 die Grundlage der „Erklärung von Bern“ geschrieben hatte, publizierte 1974 ein Buch mit dem Titel „Der Wahnwitz des Wachstums“. ${ }^{104}$ Dabei wandte er wieder dieselbe Methode an wie bei seinem Buch über Calvins Wirtschaftsethik, das die Grundlage der „Erklärung von Bern“ gebildet hatte: Diesmal interpretierte er den Calvinismus nicht mehr vor dem Hintergrund der Nord-Süd-Frage, sondern vor jenem der Umweltfrage. Nicht nur die Aktivistinnen und Aktivisten im Umfeld der „Erklärung von Bern“, die Mitte der 1970er-Jahre die Jutetasche propagierten, räumten dem Umweltschutz eine vorrangige Bedeutung ein. Auch die Vätergeneration, die sich bereits von der EvB zurückgezogen hatte, übernahm und integrierte das Thema Wachstumskritik. Dies passierte nicht nur bei den Schweizer Theologen, sondern auch auf globaler Ebene. So übernahm der ÖRK 1974 die Umweltthematik, ein Jahr später wurde sie gemäss Beschluss zu einem Arbeitsschwerpunkt des ÖKR. ${ }^{105}$ Allerdings war der Basler Barth-Schüler Lukas Vischer von 1961 bis 1980 beim ÖRK als Forschungssekretär bzw. Direktor angestellt, womit er die Ausrichtung der Organisation bedeutend mitgestaltete. ${ }^{106}$ Die Beschäftigung des Basler Bürgertums mit dem Naturschutz war ebenso traditionell wie die Unterstützung der Mission und reichte weit in das 19. Jahrhundert zurück. ${ }^{107}$ Als 1972

103 N. Klein: No Logo, xviii.

104 Biéler, André: Der Wahnwitz des Wachstums. Vom Warnruf der Wissenschaftler zum Appell der Kirchen (Freiburg i.Üe. 1974).

105 A.-M. Holenstein-Hasler, R. Renschler, R. H. Strahm: Entwicklung heisst Befreiung, 98.

$106 \mathrm{http} / / /$ www.lukasvischer.unibe.ch/ (28.3.2018).

107 Michael Baumann, Pioniertat mit nachhaltiger Wirkung, NZZ, 20.6.2014. B. Mahler: ,umdenken - umschwenken', 17-18. 
die „Grenzen des Wachstums“ ausgerufen wurden, war dies für die Basler Theologen keine Überraschung. Die Phase, in der sich die Vertreter der Kirchen um komplizierte ökonomische Zusammenhänge kümmerten und versuchten, die Bevölkerung für die trockene Materie der Handelstheorie $\mathrm{zu}$ gewinnen, war schnell vorüber. ${ }^{108}$ Sie hatte höchstens ein Jahrzehnt gedauert. Im Nachhinein scheint es, dass etwa Christoph Eckenstein die interkonfessionelle Konferenz im Bundeshaus von 1970 stark geprägt hat und für deren klare handelspolitische Ausrichtung verantwortlich zeichnete. Eckensteins früher Tod 1974 steht denn auch symbolisch für das Sterben der UNCTAD-Anliegen innerhalb der Dritte-WeltBewegung. Rudolf Strahm liess sich vom ursprünglichen Prebisch-Singer-Standpunkt abbringen, konzentrierte sich bald auf den Finanzplatz Schweiz und war ab 1978 nicht mehr für die EvB tätig. Somit war in der Schweizer Dritte-Welt-Bewegung keine starke Persönlichkeit mehr mit von der Partie, welche die UNCTADAnliegen weiter hochgehalten hätte. Während Max Geiger 1978 verstarb, gehörte Jacques Rossel von 1968 bis 1980 zum Exekutivausschuss des ÖRK und trug dessen Unterstützung der Wachstumskritik nach 1974, wie auch Lukas Vischer, mit. ${ }^{109}$ Allen war die Barthsche Grundannahme gemeinsam, dass die Theologie der erweiterten gesellschaftlichen Selbstreflexion dienen sollte. Während Karl Barth sich in der Zeit vor und nach dem Zweiten Weltkrieg für die soziale Frage in der eigenen Gesellschaft eingesetzt hatte, setzte sich die zweite Generation, zu der etwa sein Schüler Max Geiger gehörte, für die Entwicklungsfrage ein. Diese christliche bzw. typisch Barthsche Selbstreflexion, die bei den Initianten der „Erklärung von Bern“ ersichtlich ist, hat sich in den 1970er-Jahren auf den Bereich Umweltschutz übertragen. Auch wollten die Initianten der „Erklärung von Bern“ den eigenen Konsum einschränken, den eigenen Verbrauch reduzieren und selbst ihren Beitrag leisten. ${ }^{110}$ Auch Anne-Marie Holenstein, die einen christlichen Hintergrund hatte und selbst eine ökumenische Zeitschrift gegründet hatte, spricht von „Gefühlen zärtlicher Verantwortung für unseren blauen Planeten““.111

108 Siehe zu dieser kurzen Phase auch C. Saunders: British Humanitarian, Aid and Development NGOs.

109 http://www.lukasvischer.unibe.ch/ (28.3.2018), S. Rytz: Rossel, Jacques.

110 Lukas Vischer gründete 1986 den ökumenischen Verein oeku Kirche und Umwelt sowie 1998 das ECEN European Christian Environmental Network. Siehe Vischer, Lukas (Hg.): Listening to Creation Groaning. Reports and Papers from a Consultation on Creation Theology organized by the European Christian Environmental Network at the John Knox International Reformed Center from March 28 to April 1st, 2004 (Genf 2004) sowie http://www.lukasvischer.unibe.ch/ (28.3. 2018).

111 A.-M. Holenstein-Hasler, R. Renschler, R. H. Strahm: Entwicklung heisst Befreiung, 193. 
Der Calvinist André Biéler bleibt hier näher bei der Tagespolitik und den Menschen der Dritten Welt. In seinem Buch „Der Wahnwitz des Wachstums“ verbindet er die ursprünglichen Anliegen der EvB mit der Wachstumskritik. Er zitiert den Niederländer Sicco Mansholt, der als Präsident der Europäischen Kommission sehr von der Studie „The Limits to Growth“ beeindruckt war. Mansholt stand der Europäischen Kommission nur kurz vor, stand aber am Anfang der Bestrebungen der EWG, Umweltstandards einzuführen und äusserte sich dahingehend, dass er das bestehende Wirtschaftssystem des goldenen Zeitalters der Globalisierung der 1950er- und 60er-Jahre für falsch halte und eine Neuausrichtung auf Umweltschutz und immaterielle Güter wie Glück und Zufriedenheit oder Lebensqualität anstrebe. ${ }^{112}$ Damit nahm auch die Politik wachstumskritische Ideen auf, die in der Uruguay-Runde des GATT zu Schutzklauseln für Umweltstandards führten. Diese wiederum öffneten Tür und Tor für protektionistische Gesetze, die Europa als wirtschaftliche Festung vom Rest der Welt schützen sollte. ${ }^{113}$ Biéler nimmt auch in „Wahnwitz des Wachstums“, wie bereits in seinem früheren Buch von 1966, die Position ein, dass ein umweltbewusstes Verhalten schlicht ein christliches Verhalten sei. Oder, salopp ausgedrückt, dass die Calvinisten es doch immer schon gewusst hätten: „Auf einmal beginnt also die Wissenschaft die alten göttlichen Gesetze neu zu verkünden, die an und für sich die Christen der Welt hätten zur Kenntnis bringen sollen“, schrieb er spöttisch zu „The Limits to Growth“ und meinte weiter: „Die Christen haben jahrhundertelang die Enthaltsamkeit im Umgang mit den Gütern dieser Welt und den freiwilligen Verzicht zugunsten des Nächsten gepredigt.“114

Es fiel den Theologen um die „Erklärung von Bern“ sehr viel leichter, einen theologischen Zugang zu Umweltschutz und Wachstumskritik zu finden als zu den UNCTAD-Anliegen, die doch grundsätzlich Konsum und Wachstum forderten. Obschon sich die protestantischen Theologen rational mit den UNCTAD-Forderungen abgefunden hatten, durften sie nun endlich wieder ihre tief verwurzelte pietistische Genügsamkeit zum Tragen bringen. Die pietistisch-protestantische Industrialisierungskritik war denn auch nie ganz verschwunden. Bereits 1970, zwei Jahre nach der Publikation der „Erklärung von Bern“, als die EvB einen weiteren, ausführlicheren Text vorbereitete, ergänzte Max Geiger folgenden Satz: „Erde, Wasser und Luft müssen gegen die zerstörende Auswirkungen der Indu-

112 A. Biéler: Wahnwitz des Wachstums.

113 Senti, Richard: WTO. Die heute geltende Welthandelsordnung (Zürich 2014), 14-16, Bhagwati, Jagdish: Trade Liberalisation and 'Fair Trade' Demands: Addressing the Environmental and Labour Standards Issues, in: World Economy 18/6 (1995) 745-759.

114 A. Biéler: Wahnwitz des Wachstums, 107-108. 
strialisierung geschützt werden. “115 Die Publikation von „The Limits to Growth“ war für bürgerliche Theologen wie Geiger, Vischer und Biéler eine willkommene Bestätigung ihrer Grundhaltung.

Auch in den 1970er-Jahren, nachdem sich die Theologen der ersten Generation aus dem Organisationsaufbau der EvB zurückgezogen hatten, spielte die Kirche weiterhin eine bedeutende Rolle, wenn auch mehr im Hintergrund. So gab etwa der ÖRK bzw. Lukas Vischer kurz nach dem Erscheinen von „The Limits to Growth“ und „Small is Beautiful“ bei Jonathan Power und Anne-Marie Holenstein die Studie zum Thema Welternährung in Auftrag. ${ }^{116}$

\subsection{Bananenfrauen und Dritte-Welt-Läden: von der Systemkritik zum Konsum}

Die Rolle der Frauen in der Konzeptänderung des Fair Trade ist ein Thema für sich, das hier nicht abschliessend erörtert wird. Gerade in der Schweiz fiel die Zeit nach 1968 in eine Phase, in der Frauen mit der Einführung des Frauenstimmrechts 1971 überhaupt erst zu politischen Aktivbürgerinnen wurden. Im globalen Kontext waren die Jahre nach 1968 auch eine Phase der Frauenbewegung, die teilweise bzw. nach Deutungsart als reaktionär beschrieben werden kann. ${ }^{117}$ Noch 1958 hatte die Schweizer Frauenrechtlerin Iris von Roten in ihrem feministischen Manifest „Frauen im Laufgitter“ beschrieben, wie Frauen sich durch Fertigprodukte, Konserven und elektronische Haushaltgeräte von der lästigen Hausarbeit befreien können. ${ }^{118}$ Im Einklang mit der internationalen Frauenbewegung dieser Zeit, stellte sich von Roten auch gegen das Stillen, um nach der Geburt möglichst rasch wieder ihre Bewegungsfreiheit zurückzuerhalten. ${ }^{119}$ Die Umweltbewegung und die Fair-Trade-Bewegung widersprachen ab Mitte der 1970er-Jahre diesen Forderungen und vollzogen gemäss Badinter einen „politischen und moralischen Bruch“ bzw. eine „Umkehrung der Werte“. ${ }^{120}$ Sie propagierte das Kochen mit

115 SozArch, EvB, Ar 430.25.1. EvB, Anfangszeit: Die Beziehungen der Schweiz zu den Entwicklungsländern. Entwurf M. Geiger (Punkt 5 Dr. Peter Gessler), undatiert.

116 J. Power, A.-M. Holenstein: World of Hunger, A.-M. Holenstein-Hasler, J. Power: Hunger.

117 E. Badinter: Der Konflikt, 46.

118 Roten, Iris von: Frauen im Laufgitter. Offene Worte zur Stellung der Frau (Bern 1958), 437438.

119 Ebd., 333-336.

120 E. Badinter: Der Konflikt, 47. Ein moralischer Bruch manifestierte sich auch in der Haltung zu sexuellen Handlungen mit Kindern. Siehe dazu Dezentrale (Hg.): Alternativ-Katalog 2 (Porrentruy 1976) 332. 
möglichst unverarbeiteten Zutaten, Hausgeburten und das Stillen, in Badinters Duktus die „ökologische Mutterschaft“. ${ }^{121}$ Tatsächlich empfahl etwa der Alternativ-Katalog unmissverständlich die Muttermilch:

Stillen:

$\mathrm{Zu}$ diesem Thema können wir nur gerade sagen, dass eine Frau, wenn immer irgendwie möglich, ihr Neugeborenes stillen sollte. ${ }^{122}$

Gerade der Nestlé-Prozess zwischen Nestlé und der Arbeitsgruppe Schweiz-Dritte Welt in den 1970er-Jahren, in der schweizergeschichtlichen Literatur bis anhin als politisches Paradestück der 68-Generation gegen kapitalistische Grosskonzerne interpretiert, wurde in der Bevölkerung als ein Verdikt über das Stillen empfunden. Badinter hat aufgezeigt, wie die Dritte-Welt-Bewegung mit ihrem Einsatz gegen die Milchpulverindustrie zu einer Allianzpartnerin der reaktionären Stillbefürworterinnen im Westen wurde. ${ }^{123}$ Ein Basler „Fasnachts-Schnitzelbangg“ fing diese Stimmung in der Bevölkerung wie folgt ein:

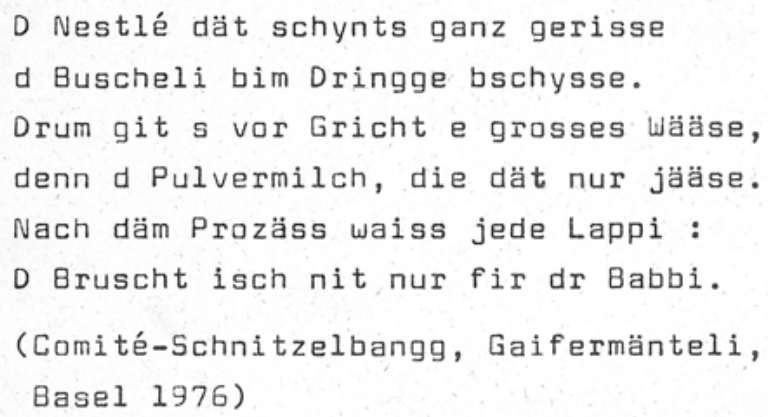

Abb. 5: Schnitzelbangg zum Nestlé-Prozess (1976)

Neben der Theorie, die diesem Lebensstil zugrunde lag, kam auch die Praxis hinzu, die in der Schweiz so aussah, dass viele Frauen auch noch zwischen Mitte der 1970er-Jahre und in den frühen 80ern längere Zeit ausschliesslich Hausfrau und Mutter waren. Während Rudolf Strahm die Prebisch-Singer-These in die EvB

121 E. Badinter: Der Konflikt, 47. Siehe zu Hausgeburten, Stillen und Kleinkinderernährung Dezentrale: Alternativ-Katalog 2, 325-334.

122 Ebd., 330.

123 E. Badinter: Der Konflikt, 94-97. 
einbrachte, setzte sich Anne-Marie Holenstein mit Hilfe der Hauswirtschaftslehrerin Susanne Krebs dafür ein, den Aspekt des bewussten Konsums zur Sprache zu bringen. ${ }^{124}$

Ab Mitte der 1970er-Jahre entstanden unter der Ägide der EvB zahlreiche Kochbücher und Broschüren, ausserdem wurden Kochkurse und Workshops abgehalten, die Hausfrauen zu einem bewussten Einkaufen animieren wollten. ${ }^{125}$ 1975 lanciert Anne-Marie Holenstein im Rundbrief das Thema „Die Dritte Welt in unserer Küche“. Der damalige Unterschied in männlichen und weiblichen Lebenswelten zeigt sich darin, dass sie sich im Rundbrief an Frauengruppen richtete. ${ }^{126}$ Nach dem Weggang Strahms 1978 verschob sich der Fair-Trade-Aspekt von der Landesgrenze in den Einkaufskorb. Sehr schnell wurde die Entwicklungspolitik nur noch zu einem Bestandteil des bewussten Konsums, der mit den Aspekten Gesundheit, Tierschutz und Umwelt faktisch konkurrierte. ${ }^{127}$ Gerade diese Konkurrenz der Themen war für Laien bzw. für Nicht-Ökonomen auf den ersten Blick kaum erkennbar. Ebenfalls war wohl aus der Innensicht der „Küche“ nicht ersichtlich, wie der Fokus auf den bewussten Konsum im Einkaufskorb von der makroökonomischen, politischen Ebene ablenkte. Insbesondere brachten die Kochbücher und das später folgende Fair-Trade-Label eine Vereinfachung, klar erkennbare Regeln, die man bzw. frau ohne intellektuellen Aufwand einhalten konnte. Es reichte, die Anleitungen im Kochbuch zu befolgen, eine Reflexion erübrigte sich. Im kulturpessimistischen Duktus Wilhelm Röpkes fand eine „Vermassung“ des Fair-Trade-Gedankens statt. ${ }^{128}$ Jede Hausfrau konnte gerechten Handel noch vor dem Mittagessen praktizieren. Im Verständnis der Initianten der Erklärung erforderte ein Umdenken allerdings mehr, nämlich eine ständige, tiefe Reflexion, die, so ist implizit anzunehmen, ein Mass an Bildung und Zeit voraussetzte. So bemerkte Jacques Rossel selbstkritisch in Bezug auf seine eigenen Kampagnen gegen das Apartheid-Regime in Südafrika: „Die christliche Ethik ist nicht ein Kochbuch. Das Gute wird nicht nach feststehenden Regeln getan. Jede ,gute Tat' unterliegt der Reflexion. “129 Wiederum zeigte sich, wie die Dialektik der tiefen Reflexion und der massentauglichen Botschaft auch nach dem Wegfall der Kirche als Rahmeninstitution weiterhin unlösbar im Raum stand.

Die Fair-Trade-Bewegung der 1980er- und 90er-Jahre ging aus zwei Strömungen hervor, wobei sich die eine dominant durchsetzte. Die eine - sie war aus

124 A.-M. Holenstein-Hasler, R. Renschler, R. H. Strahm: Entwicklung heisst Befreiung, 197.

125 K. J. Kuhn: Entwicklungspolitische Solidarität, 267.

126 A.-M. Holenstein-Hasler, R. Renschler, R. H. Strahm: Entwicklung heisst Befreiung, 193.

127 SozArch, EvB, Ar 430.30.8. Aktion „Hunger ist ein Skandal“ 1981-1982.

128 W. Röpke: Die Gesellschaftskrisis, 316.

129 J. Rossel: Leben in ökumenischer Weite, 291. 
der Prebisch-Singer-These entstanden - war jene des Alternative Trading, im Geist des Ujamaa-Pulverkaffees. Hier ging es darum, ein alternatives Handelssystem, alternative Kanäle und Verkaufsstellen einzurichten. Das Ziel bestand darin, grossen Firmen wie Nestlé und etablierte Supermärkte zu schwächen und deren Macht zu brechen. Die andere Strömung war jene, die von Frauen und Konsumentinnen ausging und lediglich eine bessere Bezahlung der Arbeiterinnen und Arbeiter, also einen gerechten Preis, den christlichen iustum pretium, forderte. Sie verlangten von den grossen Konzernen und Supermärkten lediglich einen freiwilligen Aufpreis für tropische Produkte, ohne ansonsten an den Strukturen zu rütteln oder diese analysieren zu wollen. Betrachtet man die Frauenfelder Frauengruppe, die vom Grossverteiler Migros eine bessere Bezahlung der Bananenarbeiter forderte, lässt sich im Rückblick feststellen, dass der Supermarkt damals erstmals von diesem Konsumentenwunsch hörte und ihn danach mit verschiedenen Produktlinien auch einführte. Die Führung der Migros begriff offensichtlich nicht, welches Kundensegment sie hier zunächst brüskierte. ${ }^{130}$ Schliesslich war es selten, dass sich Kunden mit ihren Wünschen und Visionen für die Zukunft so klar ausdrückten und sich damit bei der Geschäftsleitung meldeten. Die Migros vermutete fälschlicherweise politischen Aktionismus. Die Forderungen der Bananenfrauen zielten jedoch keineswegs darauf ab, mit Migros zu konkurrieren und Kosten zu verursachen. Die Forderungen waren mit der Organisation eines Supermarkets durchaus kompatibel. Es waren die Frauenfelder Bananenfrauen, die 1973 ihre Bananen mit einem Symbol markierten und somit eine Entwicklung vorspurten, die zum Gütesiegel führte. Ein Aufkleber mit einer schwarzen Hand kennzeichnete während der Frauenfelder Bananenaktionen die Bananen. ${ }^{131}$ Auch in die M-Frühling-Bewegung von 1980 bzw. während der EvB-Aktion „Globaler Supermarkt“ brachte Anne-Marie Holenstein die Idee des Gütesiegels ein, zudem liess sie eine Studie dazu verfassen. ${ }^{132} 1983$ gab jedoch nicht die EvB, sondern das katholische Schweizer Hilfswerk Brot für Brüder den Auftrag zu einer Studie über ein entwicklungspolitisches Gütesiegel. ${ }^{133}$ Dieses Gütesiegel lässt sich ziemlich klar der zweiten Strömung zuordnen und wurde über die Frauennetzwerke auf die Traktandenliste der Hilfswerke und Supermärkte gespült.

130 B. Mahler: ,umdenken - umschwenken', 72-75.

131 A.-M. Holenstein-Hasler, R. Renschler, R. H. Strahm: Entwicklung heisst Befreiung, 65.

132 SozArch, EvB, Ar 430.41.1. Textilien, Mappe 3: Adrian Stahel an EvB, 18.8.1980 Kurzgutachten [zur Einführung eines Güte-Schlechte- oder Labelzeichens in der Schweiz]. A.-M. Holenstein-Hasler, R. Renschler, R. H. Strahm: Entwicklung heisst Befreiung, 209, A.-M. Holenstein: Jute statt Plastik, 190 - 196.

133 A.-M. Holenstein-Hasler, R. Renschler, R. H. Strahm: Entwicklung heisst Befreiung, 219. 
Die Vorgeschichte der Fair-Trade-Zertifikate ist denn auch in erster Linie die Geschichte eines Abschieds der NGOs von den akademisch akzeptierten Wirtschaftswissenschaften, sei dies nun vor oder hinter dem Eisernen Vorhang. Ironischerweise ist es auch die Geschichte eines rationalen Anpassens des Angebots an die Nachfrage. Darauf hat auch die schweizergeschichtliche Forschung zu 1968 bereits hingewiesen:

Denn parallel zur jugendlichen Rebellion haben sich neue Märkte entwickelt, die die Nachfrage nach mehr Selbstverwirklichung und Individualität mit einem rasant wachsenden Angebot an Musik, Kleidern und anderen Konsumartikeln befriedigten. ${ }^{134}$

Die EvB produzierte zwar ab Mitte der 1970er-Jahre eine eigene paraakademische Lehre zur Nord-Süd-Gerechtigkeit, doch immerhin blieb sie dieser paraakademischen Wissenschaftlichkeit treu und machte sie zu ihrer Kernkompetenz. Das kommerzielle Tagesgeschäft des Fair Trade stiess die EvB 1977 ab. Von da an beteiligte sie sich nur noch auf theoretische Weise am Aufbau des Fair-Trade-Gütesiegels. Der tatsächliche Ein- und Verkauf von Produkten und deren Zertifizierung wurde ab 1977 von anderen betrieben und die EvB schwebte über diesem Tagesgeschäft. So hatte sie zwar einerseits nichts mit den zahlreichen ideellen Einbussen und Kompromissen zu tun, die der faktische Fair-Trade-Betrieb erforderlich machte, andererseits musste sie sich aber auch nicht damit beschäftigen und konnte aus der Ferne die Entwicklung des Gütesiegels und der Kommerzialisierung des Fair Trade absegnen. Bereits während der Ujamaa-Aktion hatte Rudolf Strahm festgestellt, dass die Pulverkaffeefabrik in Bukoba in Tansania mit Nestlé-Technologie ausgerüstet wurde. ${ }^{135}$ Weitere ähnliche Abstriche dieser Art am ursprünglichen Ideal des Alternativen Handels sollten kontinuierlich folgen, allerdings nicht mehr innerhalb der Organisation EvB, sondern bei den Bananenfrauen, der OS3 oder im Schweizerischen Verband der Dritt-Welt-Läden. Bereits in den 1970er-Jahren, vor der Gründung der OS3, rechneten die in einem Verband zusammengeschlossenen Dritte-Welt-Läden der Schweiz der EvB vor, dass ihre Kundinnen und Kunden Rohwaren wie Kaffee, Bananen und Zucker aus der Dritten Welt nachfragten und schlichtweg keine Nachfrage nach industriell verarbeiteten Produkten aus alternativen Produktionsformen bestehe. ${ }^{136} \mathrm{Nicht}$ einmal die Kunsthandwerksgegenstände, die in den 1960er-Jahren eigentlich das Hauptsortiment der Dritte-Welt-Läden ausmachten, wurden von den Kundinnen

134 B. C. Schär, R. Ammann, T. Färber, S. Bittner, M. Hofer, Y. Niederhäuser, V. Sperisen, M. Griesshammer, R. Fischer, M. Schär, R. Schär, E. Vaudan: Bern 68, 8.

135 A.-M. Holenstein-Hasler, R. Renschler, R. H. Strahm: Entwicklung heisst Befreiung, 130.

136 SozArch, Claro 1010.2. OS3 Gründung: Vorschläge für Statuten. 
und Kunden nachgefragt. Die Jutetaschen bildeten hier die Ausnahme, die die Regel bestätigte. Der Ujamaa-Kaffee, der eher im Rahmen einer politischen Aktion auf der Strasse an Marktständen verkauft wurde, war trotz seiner fraglichen Qualität ein kommerzieller Erfolg und bestätigte ebenfalls als Ausnahme die Regel. Während die ersten Fair-Trade-Aktivistinnen und -Aktivisten verschiedene Theorien mischten und abänderten, wurden sie gleichzeitig von der ökonomischen Realität - oder in den Worten Al Imfelds: von den „Eigengesetzlichkeiten“, die sie gerne übersahen - übermannt. ${ }^{137}$

Während Strahm und seine Volontäre zunächst die Pulverkaffee-Kampagne durchzogen und dann die Jute-statt-Plastik-Kampagne, die auch von politischem Säbelrasseln begleitet war, gab es gleichzeitig auch andere Strömungen, die medial weniger präsent waren. Aus Missionsbasaren und Verkäufen von Kunsthandwerk durch Hilfswerke waren in einem fliessenden Übergang in den 1970erJahren Dritte-Welt-Läden entstanden, die ebenfalls Kunsthandwerk aus Entwicklungsländern verkauften. Sie hatten sich wie erwähnt in einem Art Branchenverband zusammengeschlossen und gehörten durch diesen zum inneren Kreis der EvB. ${ }^{138}$ Auch die Bananenfrauen gehörte dem Kreis um die EvB an. Mehrere Frauen, die mit der Pfarrersfrau Ursula Brunner zusammenarbeiteten, hatten sich in Frauenfeld zusammengeschlossen, um Bananen zu verkaufen, für deren Produktion die Plantagenarbeiter einen gerechten Lohn erhalten hatten. ${ }^{139}$ Während die EvB nur einzelne, medial begleitete Kampagnen durchgeführt hatte, waren die Inhaber von Dritte-Welt-Läden, die im Stillen und dauerhaft ihre Produkte abzusetzen hatten, aber auch die Gruppe der Hausfrauen der Bananen-Aktion näher bei der Konsumentin bzw. beim Konsumenten. Offensichtlich hatten viele Beteiligte die Grundaussage der Prebisch-Singer-These bzw. die ultimative Wichtigkeit der lokalen Verarbeitung für die Entwicklungsländer nicht begriffen. Strahms unermüdliche Belehrungen, seine einfachen, anschaulichen Grafiken hatten keine Wirkung gezeigt. Auch das Komitee der EvB, das sich genauer mit der Theorie befasst hatte, summierte einmal in einer Nachbesprechung der Kampagnen von 1975: „Mit der UNCTAD ist keine breite Bevölkerung erreichbar“ ${ }^{140}$

$\mathrm{Zu}$ einer ähnlichen Einsicht kamen die Aktivisten in Grossbritannien. Nach der Publikation der „Haslemere Declaration“ 1968 hatten sich auch in Grossbritannien freiwillige Studiengruppen gebildet, die sich der Handelspolitik annah-

137 A. Imfeld: Die „Erklärung von Bern“ in der Krise.

138 SozArch, Claro 1011.1. Liste der Gründungsmitglieder der Vereinigung Dritte-Welt-Läden Schweiz (V3WL Schweiz).

139 A.-M. Holenstein-Hasler, R. Renschler, R. H. Strahm: Entwicklung heisst Befreiung, 65. 140 SozArch, EvB, Ar 430.61.1. GV 1975: Beschlussprotokoll. 
men. ${ }^{141}$ Doch diese erste, politisch-akademische Fair-Trade-Bewegung hatte sich bald selbst erschöpft und machte wiederum dem klassischen Bild des hungrigen afrikanischen Kindes Platz, mit dem Oxfam und andere britische Entwicklungsorganisationen seit den 1960er-Jahren erfolgreich Spenden gesammelt und eine professionelle NGO-Struktur aufgebaut hatten. Die frühere Oxfam-Aktivistin Maggie Black schrieb dazu:

\begin{abstract}
A hundred or so committed development action groups beavered away, trying to disentangle growth rates from commodity agreements, unearth the mysteries of ODAs and GATTs, unhook multilaterals from intergovernmentals, and work out where the poor fitted in. But for all the achievements of the emerging development lobby, no-one could pretend that ' 1 per cent of GDP' and 'fair trade' evoked in the public mind the passionate concern that a Biafran child could conjure [...]. ${ }^{142}$
\end{abstract}

Wie Black für die britische Oxfam schreibt, war die Arbeit einer EntwicklungsNGO schlicht nicht möglich ohne „passionate concern“, ohne eine emotionale Beteiligung der Öffentlichkeit. Handelspolitik war schlicht eine zu trockene Materie, um beim Zielpublikum Emotionen auszulösen. Zudem weist Maggie Black in diesem Zitat und in ihrem ganzen Buch über Oxfam auf die Bedeutung des Bildes hin: Zunächst brauchte es ein Bild, um die Aufmerksamkeit und die Emotionen des Publikums zu wecken. Kein Text und keine noch so überzeugende Infografik konnte denselben Effekt erreichen wie der direkte Blick aus den grossen Augen eines hungrigen afrikanischen Kindes. Zudem brauchte es beim Publikum die Verknüpfung zwischen diesem Bild und der Arbeit der NGO. Im Falle Oxfams fand in den 1970er-Jahren ein Übergang vom Bild des hungernden afrikanischen Kindes zu jenem des glücklichen Kleinbauern statt. Dies war eine grundlegende und nicht unbestrittene Konzession Oxfams an die frühe akademisch-ökonomische Haslemere-Bewegung. ${ }^{143}$ Dieser Wechsel in der Bildsprache stand für den Paradigmenwechsel in der Entwicklungspolitik - von der Entwicklungshilfe zur Hilfe zur Selbsthilfe - und insbesondere eine Abkehr von der Food Aid. ${ }^{144}$ Auch in der Schweiz wandte sich die Bewegung Ende der 1970er-Jahre von den Texten und Infografiken ab und steuerte hin zum Bild des glücklichen Kleinbauern sowie zum schriftlosen Symbol, das stellvertretend für das Bild des glücklichen Kleinbauern stand.

Die Emotionen der interessierten Öffentlichkeit mit einer begrenzten Aufmerksamkeitsspanne oder auch das simple Räsonnement von Hausfrauen, die

141 M. Hilton: International Aid and Development NGOs.

142 M. Black: Oxfam the First 50 Years, 159.

143 Ebd., 69.

144 C. Gerlach: Famine Responses, 930. 
einfach helfen wollten, waren stärker als Rudolf Strahm, Jonathan Power und andere akademische Einzelkämpfer ausserhalb der Universitäten, die nicht mehr die ganze wissenschaftliche Gemeinschaft um sich hatten, um umfassende Studien zum Thema zu generieren und die neueste Forschung zu rezipieren. Die Systemkritik von 1968 erschöpfte sich nach einigen Jahren und wich dem Fokus auf den Konsum.

\section{6 „Weniger nehmen“: Abschied von der Makroökonomie}

Auf der interkonfessionellen Konferenz in Bern von 1970 forderte die Dritte-WeltBewegung vom Bund, zukünftig in Vernehmlassungen zu Dritte-Welt-Vorlagen einbezogen $\mathrm{zu}$ werden. ${ }^{145}$ Dieser Forderung wurde stattgegeben. Schon 1974 wurde die EvB zur Vernehmlassung zum Entwicklungshilfegesetz eingeladen. ${ }^{146}$ Damit wurde sie in die Debatte um Entwicklungshilfe einbezogen und von dieser vereinnahmt, obwohl sie doch hauptsächlich Strukturveränderung der Wirtschaft nach dem Slogan „Handel statt Hilfe“ verlangt hatte. Diese Vernehmlassung führte insbesondere dazu, dass der EvB-Sekretär Rudolf Strahm viel Zeit darauf verwandte und deshalb andere neoprotektionistische Entwicklungen übersah. Die EvB wurde Opfer ihres Erfolgs. Ihre Wünsche wurden derart schnell und in einem Ausmass erhört, dass sie in der organisationalen Entwicklung überrumpelt wurde und nur noch reagierte, anstatt vordachte.

Dabei hatte die Bewegung mit der dritten grossen Zusammenkunft im Tagungszentrum Gwatt im November 1974 einen sehr aktiven konzeptionellen Schritt vorgenommen. „Wie kommen wir aus der Sackgasse der verbalen Information“ war der Titel des „entwicklungspolitischen Aktions-Workshops“, der als „Offene Tagung für Personen und Gruppen, die entwicklungspolitisch engagiert sind oder sich engagieren wollen“ ausgeschrieben war. ${ }^{147}$ In Gwatt sollten letztmals die alte und die junge Garde, die Freiwilligen und die Angestellten zusammentreffen und sich als Einheit verstehen. Die Resultate der Tagung von Gwatt sind in den Akten der EvB nicht schriftlich bzw. protokollarisch hinterlegt. Auch dies ist ein Hinweis darauf, dass es sich hier um einen freiwilligen und spontanen Austausch der Bewegung handelte. Die Resultate und die Richtungsentscheide, die das Treffen in Gwatt von 1974 zeitigten, sind somit erst im Nachhinein re-

145 H. Schmocker, M. Traber: Schweiz-Dritte Welt, 131.

146 Unter SozArch, EvB, Ar 430.11 „Deutschschweizer-Komitee“ fehlen die Jahre 1974 und 1975. Daher wird hier insbesondere auf R. Spörri: Einfluss der Erklärung von Bern verwiesen.

147 SozArch, EvB, Ar 430.27.1. Ujamaa-Kaffee, 1973-1977. Entwicklungspolitischer AktionsWorkshop, Gwatt, 23./24.11.1974 [Ankündigung]. 
konstruierbar. ${ }^{148}$ Offensichtlich ist jedoch, dass dem Abschied von der Makroökonomie ein Abschied von der „Sackgasse der verbalen Information“ und damit der Schriftlichkeit voranging. Die Bewegung verstand nun schriftliche Manifeste wie die „Erklärung von Bern“ oder die „Haslemere Declaration“ sowie die zahlreichen Bücher, die seit 1968 aus der Feder der Aktivisten entstanden waren, als „Sackgasse“.

Die Tagung von Gwatt von 1974 markierte den Abschied von der „verbalen Information“ und den Übergang zu entwicklungspolitischen Aktionen. Die Teilnehmer vertraten aber gleichzeitig sehr unterschiedliche Ideen eines gerechten Nord-Süd-Handels. So beschloss man eine weitere, von der EvB orchestrierte Ujamaa-Pulverkaffee-Aktion und Anne-Marie Holenstein lancierte ihre Idee des Fleischverzichts, zudem hing die Idee einer Volksinitiative im Raum. Somit herrschte in Gwatt eine Gleichzeitigkeit des Ungleichzeitigen auf drei Ebenen. Einerseits brachte die alte Garde um Roy Preiswerk die Idee einer entwicklungspolitischen Volksinitiative auf und vertrat somit weiterhin die Ebene des politischen Bürgeraktivismus. ${ }^{149}$ Strahm und Holenstein vertraten bereits die nächste Ebene der NGO-Kampagnen, wobei Strahm mit dem Ujamaa-Pulverkaffee noch weiterhin bei der Prebisch-Singer-These und Holenstein schon bei der Wachstumskritik angelangt war. Diese bereits sehr heterogene Konzeption wurde daraufhin nochmals aufgemischt, als vor allem Strahm, aber mit ihm die ganze Bewegung, begann, sich mit der Vorlage für ein eidgenössisches Gesetz über die Entwicklungszusammenarbeit zu beschäftigen. Den Einfluss, den die EvB auf die Vorlage nahm, hat Spörri im Detail nachgezeichnet. ${ }^{150}$ Hier ist zu ergänzen, dass bei Strahms Einwänden bereits sehr stark die „Abkopplung“ und die grundsätzliche Ablehnung privater Direktinvestitionen zum Tragen kamen. Damit wurde eine Überschneidung mit der neokonservativen Bewegung möglich, wie sie später in vielen anderen eidgenössischen Vorlagen zum Normalfall werden würde. ${ }^{151}$ Wäre das Gesetz über die Entwicklungszusammenarbeit ein paar Jahre früher vorgelegt worden, hätte es wohl anders ausgesehen. Mitte der 1970er-Jahren

148 Beschrieben ist das Treffen in A.-M. Holenstein-Hasler, R. Renschler, R. H. Strahm: Entwicklung heisst Befreiung, 124-125.

149 R. Preiswerk, G. Rist: A contre-courants, 54.

150 R. Spörri: Einfluss der Erklärung von Bern.

151 Die herausragendsten Beispiele sind die Ablehnung des Beitritts der Schweiz zu den BrettonWoods-Institutionen, als die Hilfswerke 1991 gemeinsam das Referendum ergriffen, sowie die Ablehnung des Beitritts zum EWR in der Abstimmung von 1992. In diesen Abstimmungkämpfen befand sich die Dritte-Welt-Bewegung wiederholt im selben politischen Lager wie die nationalkonservative Schweizerische Volkspartei. Die EvB hat insbesondere zum Referendum gegen den Beitritt der Schweiz zu den Bretton-Woods-Instititutionen wichtige Vorarbeit geleistet, siehe dazu SozArch, EvB, Ar 430.62. Internationaler Währungsfonds (IWF)/Weltbankgruppe. 
hatten sich in der Dritte-Welt-Bewegung jedoch bereits neue, paraakademische oder zumindest akademisch sehr umstrittene Thesen durchgesetzt. So die These der „Abkopplung“, aber auch jene der „Peripherie im Inland“, der Wachstumskritik und der Kritik an Industrialisierung und Verstädterung. Auch am rechtskonservativen Rand war unterdessen um den Nationalrat James Schwarzenbach eine nicht unbedeutende Bewegung entstanden, die in der Legislaturperiode von 1971 bis 1975 sieben Nationalratsmandate hielt. ${ }^{152}$ Während die Bewegung um Schwarzenbach vor allem die „Überfremdung“ kritisierte, setzte sie sich auch für die Bewahrung der Schweizer Landwirtschaft ein und forderte von der Schweizer Wirtschaft, in der Schweiz zu produzieren und Schweizerinnen und Schweizer einzustellen. So traf die Dritte-Welt-Bewegung, die unterdessen mit der wachstumskritischen Bewegung verschmolzen war, mit den Neokonservativen auf einem Nebenschauplatz erstmals zusammen.

So entstand denn in der Debatte um das Gesetz über die Entwicklungszusammenarbeit zum ersten Mal die „unheilige Allianz“ zwischen der Dritte-WeltBewegung und den Neokonservativen. ${ }^{153}$ Die Republikaner um James Schwarzenbach kritisierten die Entwicklungshilfe an sich und forderten, die Armen im Inland sollten nicht vernachlässigt werden. ${ }^{154}$ So heisst es nun in Artikel 9 des Bundesgesetzes über die internationale Entwicklungszusammenarbeit und humanitäre Hilfe: „Bei der Rahmenkreditvorlage sind die Lage der schweizerischen Wirtschaft und der Bundesfinanzen sowie Erfordernisse der benachteiligten Gebiete im Inland zu beachten“. ${ }^{155}$ Die EvB wiederum brachte ihr Abkopplungsdogma für die Entwicklungsländer durch. So steht in Artikel 5:

Die Entwicklungszusammenarbeit fördert
a. die Entwicklung ländlicher Gebiete;
b. die Verbesserung der Ernährungslage, insbesondere durch die landwirtschaftliche Pro- duktion zur Selbstversorgung;
c. das Handwerk und die örtliche Kleinindustrie;
d. die Schaffung von Arbeitsplätzen;
e. die Herstellung und Wahrung des ökologischen und demografischen Gleichgewichts.

152 Peter-Kubli, Susanne: Schwarzenbach, James, in: Marco Jorio (Hg.): Historisches Lexikon der Schweiz (Basel 2002-2014) http://www.hls-dhs-dss.ch/textes/d/D6678.php (24.10.2012).

153 C. W., „Soziale Befreiung“ gegen Entwicklungszusammenarbeit, NZZ, 29.5.1981.

154 R. Spörri: Einfluss der Erklärung von Bern.

155 Siehe dazu in der Systematischen Rechtssammlung des Bundes das Bundesgesetz über die internationale Entwicklungszusammenarbeit und humanitäre Hilfe vom 19.3.1976 (https://www. admin.ch/opc/de/classified-compilation/19760056/index.html) (13.9.2017). 
Aus dem Gesetzestext wird ersichtlich, wie sich die Bewegung um die EvB und mit ihr der Slogan Small is beautiful im Bereich der Entwicklungszusammenarbeit durchgesetzt hatte. ${ }^{156}$

An dieser Stelle gilt es zu ergänzen, dass das Buch „Small is Beautiful“ nicht nur ein anti-modernistisches Manifest der erwachenden grünen Bewegung war. Vielmehr war es eine Grundsatzkritik an den Wirtschaftswissenschaften, und es markierte die Spaltung der Sozialwissenschaften in die Wirtschaftswissenschaften auf der einen und die Soziologie und die Geisteswissenschaften auf der anderen Seite. Schumacher, selbst Ökonom und Schüler von John Maynard Keynes, autorisierte mit seiner Schrift die offizielle Diskreditierung der Ökonomie als Wissenschaft und die folgende Abkehr und Ignorierung ökonomischer Erkenntnisse durch die Umwelt- und Dritte-Welt-Bewegung. Schumacher qualifizierte die Ökonomie nicht als Wissenschaft, sondern als „absurd“, „zerstörerisch“ und als eine „Religion“:"157

Beispielsweise ist der zum Ökonometriker gewordene Wirtschaftswissenschaftler nicht bereit und im Allgemeinen auch nicht in der Lage, nachdem er auf seine rein quantifizierende Weise den Anstieg des Bruttosozialprodukts eines Landes um, sagen wir, fünf Prozent festgestellt hat, sich mit der Frage auseinanderzusetzen, ob das gut oder schlecht ist. ${ }^{158}$

In seiner Aufsatzsammlung „Es geht auch anders. Jenseits des Wachstums“ macht Schumacher sich Gedanken über die Aufgaben des „nach-modernen Nationalökonomen“, denn es lasse sich nicht leugnen, dass „die Volkswirtschaftler eine ganz besonders grosse Verantwortung trifft, denn sie haben sich zu den Gralshütern und Hohenpriestern der Wirtschaftsreligion gemacht. “159 Kein ,politischer Imperialismus“ habe ,je so viel Zerstörung angerichtet wie der Imperialismus der ökonomischen Denkweise“, postulierte Schumacher. ${ }^{160}$ Mit dieser Aussage übertrumpfte Schumacher seinen Mentor John Maynard Keynes, der gesagt hatte, Ideen (toter) Ökonomen würden die Politik bestimmen, ohne dies zu werten. ${ }^{161}$ In seinem Glaube an die Macht der Ökonomie blieb Schumacher ein treuer Schüler Keynes', auch wenn er den Keynesianismus der Nachkriegszeit ansonsten ver-

156 A.-M. Holenstein-Hasler, R. Renschler, R. H. Strahm: Entwicklung heisst Befreiung, 159.

157 E. F. Schumacher: Small is Beautiful, 50-54. Siehe zur Ökonomie als „Religion“ auch das Kapitel „Economic 'Science’ as Religion“ in Rist, Gilbert: The Delusions of Economics. The Misguided Certainties of a Hazardous Science (London 2011).

158 E. F. Schumacher: Small is Beautiful, 54.

159 E. F. Schumacher: Es geht auch anders, 78.

160 Ebd.

161 J. M. Keynes: The General Theory, 383. 
urteilte. ${ }^{162}$ Hauptsächlich verurteilte er aber die „Mathematisierung“ der Wirtschaftswissenschaften, die in den 1950er-Jahren mit voller Wucht einsetzte:

Mit der Perfektionierung der kalkulatorischen Methoden, mit der fortschreitenden Entwicklung von Ökonomie zur Ökonometrie, mit der Ausdehnung des wirtschaftlichen Denkens auf immer weitere Lebensbereiche - macht sich der moderne Nationalökonom immer mehr zum wirksamen Diener derjenigen Tendenz, die geradezu als Charakteristikum des modernen Zeitalters bezeichnet werden kann, der Herrschaft der Quantität. ${ }^{163}$

Damit sprach Schumacher den wunden Punkt der Wirtschaftswissenschaften an, der zur „Spaltung“ in eine akademische und eine paraakademische Ökonomie stark beitrug: Die akademische Ökonomie schlug in der Nachkriegszeit mit der „Mathematisierung“ einen Pfad ein, der die Wissenschaft auf direktestem Weg an die Spitze des universitären Elfenbeinturms führen würde. ${ }^{164}$ Nicht nur Schumacher, auch das Spätwerk seines neokonservativen Vorgängers Wilhelm Röpke wurde von der akademischen Ökonomie aussortiert und fortan als Sozialphilosophie bezeichnet. ${ }^{165}$ Interessant ist wiederum, wie sich die Aussagen von Röpke und Schumacher zur Ökonomie schon fast wörtlich decken. Der neokonservative Vordenker Russel Kirk, ein US-amerikanische Literaturwissenschaftler und ein Freund Röpkes, brachte ähnlich wie Schumacher die röpkesche Haltung zum Bruttosozialprodukt auf den Punkt: „Roepke spoke of the human condition, but Moscow, London, and Washington were obsessed by the gross national product." ${ }^{166}$ Bereits in den 1940er-Jahren hatte die neokonservative Bewegung um Wilhelm Röpke einen gewichtigen Antagonismus zwischen Moral und Empirie geschaffen, der quer durch das Links-Rechts-Schema des Kalten Kriegs gehen und von Schumacher lediglich repliziert werden würde. Schumachers Vater Hermann war Professor der Nationalökonomie in Berlin und betreute vor seiner Emeritierung 1935 Röpkes Kollegen Walter Eucken. ${ }^{167}$ Ernst Friedrich Schumacher war somit nicht nur inhaltlich, sondern auch durch seine familiäre Herkunft und intellektuelle Fundierung in der deutschen Nationalökonomie Teil der Generation um Röpke.

162 E. F. Schumacher: Es geht auch anders, 33.

163 Ebd., 58-59.

164 H. Hagemann: European Émigrés, 643, Kurz, Heinz D.: Post Scriptum, in: Heinz D. Kurz (Hg.): Klassiker des ökonomischen Denkens (München 2008-2009) 373.

165 Kolev, Stefan; Commun, Patricia (Hg.): Wilhelm Röpke (1899-1966). A Liberal Political Economist and Conservative Social Philosopher (Heidelberg 2018).

166 W. Röpke: The Social Crisis, xi.

167 Goldschmidt, Nils: Hermann Schumacher - nur ein weiterer Erbe Schmollers oder der erste Ordoliberale?, in: Historische Schulen 11 (2005) 53-93. 
Röpkes „Gesellschaftskrisis der Gegenwart“ von 1942 war im deutschsprachigen Raum eines der bedeutendsten Bücher der Kriegszeit, Schumachers „Small is Beautiful“ gehört auf internationaler Ebene zu den einflussreichsten Bücher der Nachkriegszeit, doch beide Werke wurden innerhalb der Ökonomie ignoriert. ${ }^{168}$ Die Reputation der eigenen Wissenschaft ausserhalb des universitären Elfenbeinturms sowie das Verständnis von paraakademischen Konzepten der Weltwirtschaft in der Gesellschaft ist kein Thema der akademischen Ökonomie. ${ }^{169}$ Die Wirtschaftswissenschaften haben die seit Mitte der 1970er-Jahre beobachtbare Spaltung und die Abkehr der Dritte-Welt-Aktivisten von der Makroökonomie mitzuverantworten. Sehr selten appellierten Ökonomen an die Verantwortung ihrer Zunft, sich in die öffentliche Diskussion um die Gerechtigkeit des Weltwirtschaftssystems einzubringen. ${ }^{170}$ Währenddessen hat es sich zeitgleich mit dem Erscheinen von „Small is Beautiful“ zu Beginn der 1970er-Jahre in den Geisteswissenschaften eingebürgert, der Ökonomie ihren Status als Wissenschaft schlicht abzusprechen.

Diese Entwicklung zeigt sich beispielhaft in den Publikationen der Fachleute am Institut africain bzw. ab 1973 dem IUED in Genf. Für Pierre Bungener gehörten „les économistes“ 1975 gemeinsam mit den Regierungen und Industriellen zu jenen, die an der Macht waren, „qui détiennent le pouvoir“. ${ }^{171}$ Der ab 1975 am Institut forschende und lehrende Genfer Politologe Gilbert Rist, der ab 1972 dem Vereinsvorstand der EvB angehörte, wurde zu einem international bekannten, vehementen Kritiker der Ökonomie. ${ }^{172}$ Rist schrieb ab 1975 als assoziierter Forscher des IUED seine Doktorarbeit über Entwicklungskonzepte der Schweizer Hilfswerke zwischen 1960 und 1974, die er 1978 auf Französisch und 1979 in gekürzter Fassung auf Deutsch publizierte. ${ }^{173}$ Darin zeigte er auf, wie sich im Diskurs der Schweizer Hilfswerke eine „neue“ Betrachtungsweise des Konzepts Entwicklung gegenüber dem ,alten“ der 1960er-Jahre durchsetzte. ${ }^{174}$ Anhand zahlreicher Dokumente verschiedener Schweizer Hilfswerke zeigte Rist auf, wie die Schweizer Hilfswerke zunächst die UNCTAD-Vorgaben übernahmen:

168 E. F. Schumacher: Small is Beautiful, W. Röpke: Die Gesellschaftskrisis.

169 Siehe dazu Rodrik, Dani: Economics Rules. Why Economics Works, When It Fails, and How to Tell the Difference (Oxford 2015).

170 Ebd.

171 P. Bungener: Problèmes, 9.

172 Rist, Gilbert: L'économie ordinaire entre songes et mensonges (Paris 2010), Rist, Gilbert: Le développement. Histoire d'une croyance occidentale (Paris 2007), 426-435.

173 Rist, Gilbert: Wie Weisse Schwarze sehen wie Schweizer Hilfswerke die Dritte Welt sehen (Basel 1979), 8.

174 Ebd., 9. 
Gemäss der ethnozentrischen Perspektive, die in den meisten Dokumenten der Hilfswerke vorherrscht, besteht die Welt aus einem Zentrum (den westlichen Industrieländern) und einer Peripherie. Das Zentrum verbreitet Licht, Logik, Technik, Geld, Maschinen und Entwicklungshelfer, die Peripherie versinkt in Dämmerung, traditionellen Denk- und Verhaltensweisen, archaischen Techniken, Armut, Krankheit und Analphabetismus. ${ }^{175}$

Rist nennt seine Kritik an den Hilfswerken „ethnozentrisch“, tatsächlich stammte die Zentrum-Peripherie-Theorie aus Lateinamerika. Sie wurde vom argentinischen Ökonomen Raúl Prebisch in den 1950er-Jahren vehement vertreten und er setzte sie gegen den Widerstand der westlichen Mitglieder der Vereinten Nationen in Form der UNCTAD-Doktrin durch. ${ }^{176}$ Die Schweizer Hilfswerke waren also zunächst den Vorgaben der (südlichen) Entwicklungsökonomen gefolgt, was ihnen Rist in den 1970er-Jahren jedoch als Ethnozentrismus auslegte. Tatsächlich findet sich die Rhetorik mit Begriffen wie „archaisch“ oder „traditionelle Denk- und Verhaltensweisen“ bei Entwicklungsökonomen der 1960er-Jahre. ${ }^{177}$ Prebisch selbst forderte gar die „weitgehende Transformation der Sozialstruktur“, die „wirtschaftliche Revolution“ und „Opfer“. Diese „radikale“ Rhetorik Prebischs war zunächst bei europäischen Aktivisten auf fruchtbaren Boden gefallen, wie ein Auszug aus der britischen „Haslemere Declaration“ von 1968 zeigt:

We agree with Dr. Raul Prebisch, the Secretary-General of the United Nations conference on Trade and Development (UNCTAD): In the developing world a very profound economic revolution has to take place (and) a far-reaching transformation of the social structure... This revolution is inevitable and we have to discuss what shape it must take, what degree of human sacrifice, and social and political sacrifice, or moral sacrifice, this revolution of the Third World will entail. ${ }^{178}$

Doch zu Beginn der 1970er-Jahre entwickelten Forscher am IUED und mit ihnen Aktivisten und Hilfswerke eine zunehmend kritische Haltung gegenüber der UNCTAD und der Entwicklungsökonomie, die zu einer grundsätzlich ablehnenden Haltung gegenüber den Wirtschaftswissenschaften wurde. ${ }^{179}$ Rist erklärte dies mit einer neuen Vorstellung von Pluralität der Kultur, während bis anhin in Andersartigkeit lediglich als Unterentwicklung gesehen worden war:

175 Ebd., 87.

176 J. Toye, R. Toye: Origins and Interpretation.

177 R. Jolly: A Short History, 14.

178 Bodleian Library, Oxford. Oxfam archive, MS, Oxfam. COM/3/1/12. Folder 3: Haslemere Declaration, S. 4.

179 M. Nobs-Margairaz: L’Institut africain, 86-87, A. Bänziger: Entwicklungsland Welt - Entwicklungsland Schweiz, 34. 
Das Siegesgefühl der 60er-Jahre hat hier und dort einer gewissen Bescheidenheit Platz gemacht; der Ethnozentrismus ist weniger dominant als früher, und es tauchen gewisse Anzeichen der Anerkennung von kultureller Vielfalt auf. ${ }^{180}$

Was sich in der Betrachtungsweise des Konzepts Entwicklung bei den Schweizer Hilfswerken änderte und nicht zuletzt durch Forscher am Institut africain angestossen wurde, war die Haltung gegenüber den Wirtschaftswissenschaften.

- In den Verlautbarungen der Hilfswerke zeichnen sich Veränderungen ab. Der penetrant ethnozentrische Blickwinkel, der bis Ende der 60er Jahre vorherrschte, trat nach und nach zugunsten einer offeneren Betrachtungsweise etwas in den Hintergrund.

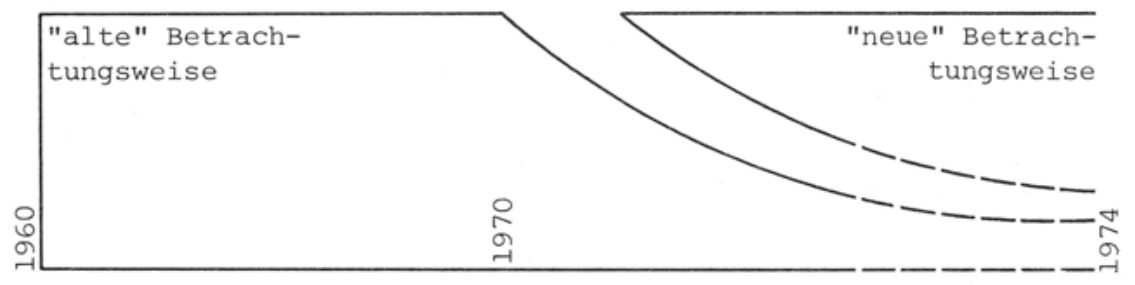

Allerdings bestehen gewisse Formen von Ethnozentrismus und Vorurteilen fort und sind bisweilen zäher als die neuen Ansätze.

Abb. 6: Die neue Betrachtungsweise des Konzepts Entwicklung gemäss Rist (1979)

Insbesondere Roy Preiswerk, Gilbert Rists Mentor am IUED, machte in seiner Haltung gegenüber den Wirtschaftswissenschaften eine Wandlung durch. ${ }^{181}$ Ein Jahrzehnt, nachdem Preiswerk Prebischs und Singers Arbeit vehement gegen neoliberale Kritiker verteidigt hatte, wurde er selbst zum scharfen Kritiker der Wirtschaftswissenschaften. Zeitgleich mit Schumacher kritisierte Preiswerk die Verabsolutierung des Wirtschaftswachstums als Wert, nannte - wie Schumacher - die Definition von Entwicklung gemäss Wohlstandswachstum „absurd“ und die Ökonomie eine „,beschränkte Disziplin“ ${ }^{182}$ Dabei fehlte bei den Nicht-Ökonomen eine Kenntnis der heterodoxen Forschung in den Wirtschaftswissenschaften. Gerade Raúl Prebischs wissenschaftliches Werk fand im Gegensatz zu seinen

180 G. Rist: Wie Weisse Schwarze, 94.

181 M. Nobs-Margairaz: L'Institut africain, 86-87.

182 R. Preiswerk: Entwicklungshilfe als Kulturbegegnung, 14-17. 
markanten politischen Aussagen kaum Beachtung. ${ }^{183}$ Nach Christoph Eckensteins Tod 1974 steuerte Prebisch einen Artikel zur Schrift bei, die im Gedenken an den Schweizer verfasst wurde. Prebisch schrieb:

Politisches Handeln geht heutzutage jeden Einzelnen etwas an; die zukünftigen Generationen können jedoch noch nicht daran teilnehmen, sich also nicht zu gewissen Problemen Gehör verschaffen, wie zum Beispiel der immer schlimmer werdenden Umweltverschmutzung, der verantwortungslosen Ausbeutung der Naturschätze, den Problemen der Bevölkerungsexplosion. [...] Es gibt keine wirtschaftliche Theorie, nach der ein für alle Male über die gerechte Verteilung der materiellen Güter entschieden werden kann. Das Problem muss also auf moralischer Basis und mit grösstmöglicher Voraussicht gelöst werden. ${ }^{184}$

Wie ähnlich waren sich Prebischs Überlegungen mit den Aussagen Schumachers, Preiswerks oder Rists! Allerdings war Prebischs Forschung zu den Auswirkungen exzessiver Industrialisierung nicht genügend in die universitäre Lehre eingeflossen. ${ }^{185}$ Derweil stiessen sich die Kritiker Schumacher, Preiswerk oder Rist am Bild des homo oeconomicus, an der Grundannahme des methodologischen Individualismus. ${ }^{186}$ Preiswerk, der sich doch eingehend mit der neoliberalen Denkschule befasst hatte, sieht das Modell des homo oeconomicus in der Tradition westlichen Denkens:

Das naturrechtliche Postulat einer ,ratio universalis', wonach die Vernunft aller Menschen gleichgeartet sei, und das liberalwirtschaftliche Postulat eines, homo oeconomicus ' im Sinne des profitorientierten Einzelmenschen sind pseudowissenschaftliche Exportprodukte des Westens. ${ }^{187}$

Die konsequente Kritik Preiswerks am Ethnozentrismus und sein Insistieren auf dem Dialog, der „Kulturbegegnung“, warfen zahlreiche relevante Forschungsfragen auf. ${ }^{188}$ Mit seiner Qualifikation eines wirtschaftswissenschaftlichen Modells als „pseudowissenschaftlich“ bereitete er allerdings den Boden für seinen Mitarbeiter Rist, der einen Dialog mit den Wirtschaftswissenschaften verweigerte und die Ökonomie als „überflüssig“ bezeichnete. ${ }^{189}$

183 J. Toye, R. Toye: UN and Global Political Economy, 138.

184 C. Eckenstein, B. Gurtner: Den Dialog erkämpfen, 228.

185 J. Toye, R. Toye: UN and Global Political Economy, 138.

186 G. Rist: Le développement, 426-435.

187 R. Preiswerk: Entwicklungshilfe als Kulturbegegnung, 41.

188 Ebd.

189 G. Rist: Le développement, 426-435. 
Al Imfeld, der wie Rist und Preiswerk zum EvB-Vorstand gehörte, begann jedoch in den frühen 1980er-Jahren - mit einer durchaus kritischen Einstellung gegenüber dem eigenen Milieu -, gewisse Aspekte des methodologischen Individualismus empirisch an der eigenen Organisation $\mathrm{zu}$ beobachten. ${ }^{190}$ Ungeachtet Imfelds poetischer Einwürfe schritt die symbolische Verdammung der Wirtschaftswissenschaft in der EvB mit Rists Aufnahme in den Vorstand der EvB 1972 und Eckensteins Tod 1974 voran. In Anne-Marie Holensteins fiktiver Erzählung über die Einführung eines Gütesiegels in der Migros von 1980, steht eine Frauengruppe einem „Wirtschaftswissenschaftler“ gegenüber, der sich gegen ihre Vorschläge sträubt. ${ }^{191}$ Der Wirtschaftswissenschaftler war vom „kompetenten Volkswirtschaftler“, der Lösungen aufzeigte, zum Problem geworden, dem „Hausfrauen“ gegenüber standen. ${ }^{192}$

Auch vor dem Hintergrund der stark aufflammenden Kritik an der Ökonomie und deren Ablehnung ist die neuerliche Zusammenkunft $\mathrm{zu}$ sehen, die die Bewegung im Umfeld der EvB in Gwatt im Jahr 1974 durchführte. Die Tagung war, wie Strahm sagte, ein wichtiger Meilenstein für die EvB. ${ }^{193}$ Im Rückblick zeigte sich anlässlich dieses Treffens erstmals auch die Widersprüchlichkeit zwischen dem Einsatz für Entwicklungsländer und jenem für die naturnahe und traditionelle Landwirtschaft im Inland. Ein Widerspruch, den die Bewegung die nächsten Jahrzehnte prominent verkörpern sollte. Mit dem Einsatz für das Gesetz über die Entwicklungszusammenarbeit zeigte sich ein weiteres Mal die Widersprüchlichkeit, die bereits im Manifest von 1968 im Kern angelegt war. Einerseits sollten Handelsstrukturen in der Schweiz verändert werden. Andererseits wurde Entwicklungshilfe als ein Geben verstanden, und die EvB prompt ins „Geben“ einbezogen. Die Theologen um die EvB hatten sich bereits 1968 nicht vollständig mit dem UNCTAD-Slogan Trade, not Aid identifizieren können, und dies kam nun beim Aufsetzen des eidgenössischen Gesetzes über die Entwicklungszusammenarbeit umso klarer zum Ausdruck.

Der mit Blick auf die Zukunft der NGOs wohl wichtigste Punkt war jedoch Artikel 11 des Gesetzes über die Entwicklungszusammenarbeit: „Der Bundesrat kann Bestrebungen privater Institutionen, die den Grundsätzen und Zielen dieses

190 A. Imfeld: Die „Erklärung von Bern“.

191 A.-M. Holenstein: Jute statt Plastik, 187.

192 Punkt 6, Die Erklärung von Bern, https://www.publiceye.ch/fileadmin/files/documents/Ue ber_uns/EvB_1968_0.pdf (28.3.2018). Siehe auch SozArch, EvB, Ar 430.25.1. EvB, Anfangszeit: Die Erklärung von Bern, März 1968. S. George: How the Other Half Dies, 295.

193 A.-M. Holenstein-Hasler, R. Renschler, R. H. Strahm: Entwicklung heisst Befreiung, 124-125. 
Gesetzes entsprechen, [...] unterstützen.“194 Damit erhielt die Zahlung von Steuergeldern an NGOs, welche sich gemäss Artikel 5 der Förderung der ökologischen landwirtschaftlichen Selbstversorgung und Kleinindustrie verschrieben hatten, die gesetzliche Grundlage. Umgekehrt hatten sich NGOs, welche staatliche Unterstützung beantragen wollten, an Artikel $5 \mathrm{zu}$ halten. Damit perpetuierte sich das Mitte der 1970er-Jahre von den Hilfswerken und Aktivisten gemeinsam festgelegte Konzept in den kommenden Jahrzehnten. ${ }^{195}$ Wie auch das DANGO-Projekt für Grossbritannien aufgezeigt hat, verlief der Aufbau des NGO-Sektors komplementär zum Ausbau des Wohlfahrtstaats. ${ }^{196}$ Der NGO-Sektor habe sich „intricatly intertwined with government“, so dass der Begriff Nichtregierungsorganisation hinterfragt werden müsste. ${ }^{197}$ Für die organisationale Struktur der Dritte-WeltBewegung bedeutete die Annahme des Gesetzes über die Entwicklungszusammenarbeit für die Organisationen selbst einen Übergang vom Geben zum Nehmen. Kurz gesagt wurden aus Privatpersonen, die sich zur Zahlung von drei Prozent ihres persönlichen Einkommens verpflichtet hatten, Angestellte in der Schweiz, deren Salär als Entwicklungshilfe zu verbuchen war. Erst durch Artikel 11, nämlich die staatliche Teilfinanzierung der Entwicklungshilfeorganisationen, wurde deren professioneller Betrieb überhaupt möglich. Der Abschied von der Makroökonomie fiel somit zusammen mit einem politökonomisch rationalen Verhalten der Akteure, die auf nationaler politischer Ebene für das Bestehen, das Wachstum und den Einfluss ihrer Organisation lobbyierten. Wie dem Lehrbuch für Politische Ökonomie entsprungen, begannen die EvB-Angestellten bewusst und systematisch, ihre „Lobby-Arbeit“ in der Politik, die sie selbst auch als solche bezeichneten (siehe Abbildung 7).

\subsection{Die Schweizer Bergbauern: die Peripherie im Inland}

Die Schweiz stellte in den 1930er-Jahren erste Weichen zum Schutz ihrer Landwirtschaft und während des Zweiten Weltkriegs folgten weitere Massnahmen zur Förderung der landwirtschaftlichen Produktion. Diese bereits faktisch vorhandene Steuerungsfunktion des Staates wurde mit den Wirtschaftsartikeln, die 1947

194 Siehe dazu in der Systematischen Rechtssammlung des Bundes das Bundesgesetz über die internationale Entwicklungszusammenarbeit und humanitäre Hilfe vom 19.3.1976 (https://www. admin.ch/opc/de/classified-compilation/19760056/index.html) (13.9.2017).

195 Siehe zu diesem Konzept insbesondere A. Bänziger: Entwicklungsland Welt - Entwicklungsland Schweiz.

196 M. Hilton: Politics of Expertise, 191-197.

197 Ebd., 254. 
Lobby-Arbeit "Regionale Entwicklungsbanken" (Nur INTEinT verwendon)

WER MACHT WAS?

\begin{tabular}{|c|c|c|c|}
\hline Annemarie & & NR & Reiniger \\
\hline Ursula & & $\begin{array}{l}\text { NR } \\
\text { SR }\end{array}$ & $\begin{array}{l}\text { Euler } \\
\text { Miville }\end{array}$ \\
\hline Urs & $\begin{array}{l}\text { Radio } \\
\text { TV }\end{array}$ & $\begin{array}{l}\text { NR } \\
\text { NR }\end{array}$ & $\begin{array}{l}\text { Schmid H. } \\
\text { Jäger F. } \\
\text { Mirjam Salzmann } \\
\text { Alex Gschwind } \\
\text { Kriessner }\end{array}$ \\
\hline Regula & TV & SP & $\begin{array}{l}\text { Eugen Fehr } \\
\text { Kommissionsleute }\end{array}$ \\
\hline Hans & & NR & Braunschweig \\
\hline
\end{tabular}

Abb. 7: Internes Dokument zur Lobby-Arbeit (1976)

vom Volk angenommen wurden, verfassungsrechtlich verankert. 1952 nahm das Volk das eidgenössische Landwirtschaftsgesetz an, das die schweizerische Landwirtschaft vom Weltmarkt ausnahm und dem Bund nochmals ausdrücklich die Kompetenzen gab, Regelungen festzusetzen und Subventionen zu sprechen. ${ }^{198}$ In den 1950er- und 60er-Jahren herrschte in der Landwirtschaftspolitik noch das klassische „Vorkriegsverständnis“: Es ging vor allem um die Steigerung der Produktivität, die ab den 1960er-Jahren zu Überschüssen führte. ${ }^{199}$ Die „Butterberge“ verliehen den Kritikern von „Überfluss“ und „Produktivität“ Rückhalt in der Bevölkerung. ${ }^{200}$ Die Dritte-Welt-Bewegung hat die schweizerische Agrarpolitik seit den 1970er-Jahren mitgestaltet. ${ }^{201}$ Gleichzeitig fand aber in der bürgerlichen Schweiz eine ideelle Neuorientierung statt, die ihren Ursprung in der Geistigen Landesverteidigung hatte und die schweizerische Landwirtschaft bzw. die schweizerischen Bauernfamilien und ihre Höfe schliesslich zum schützenswerten Kulturgut machen würde. ${ }^{202}$

198 Baumann, Werner; Moser, Peter: Agrarpolitik, in: Marco Jorio (Hg.): Historisches Lexikon der Schweiz (Basel 2002-2014) http://www.hls-dhs-dss.ch/textes/d/D13789.php (16. 8. 2012).

199 W. Baumann, P. Moser: Bauern im Industriestaat, 385.

200 A.-M. Holenstein, J. Davis: Zerstörung durch Überfluss, 64.

201 P. Moser: Stand der Bauern, 311-312.

202 A. Franc: Agricultural Protectionism. 
Bereits zu Beginn des 20. Jahrhunderts, doch insbesondere in der Kriegszeit, belebten Autoren der Geistigen Landesverteidigung das spätmittelalterliche, „erfundene“ Bild einer Schweiz als Nation der freien Bauern wieder. ${ }^{203}$ „Schweizerart ist Bauernart“ gab der Direktor des Schweizerischen Bauernverbandes Ernst Laur 1939 als Losung durch. ${ }^{204}$ Diese steht für ein Empfinden, das er nicht nur mit einem grossen Teil der Schweizer Bevölkerung, sondern mit Autoren wie Wilhelm Röpke oder dessen Protegé, Gerhard Winterberger, teilte. Der „ruralophilen“ public intellectuals gab es in der Schweiz der 1940er- und 50er-Jahren zuhauf. ${ }^{205}$ Sie bereiteten mit ihren Artikeln, Büchern und Wortmeldungen das Terrain vor, das in den 1970er-Jahren eine Neuausrichtung der Schweizer Agrarpolitik möglich machen würde. So arbeitete etwa Gerhard Winterberger, inspiriert von seinem Mentor Wilhelm Röpke, an volkskundlichen Studien zu seinem Herkunftsort, dem Haslital, und setzte sich von da an zeitlebens für die Bewahrung des Bergbauerntums in der Schweiz ein. ${ }^{206}$ Der Fokus auf den Bergbauern als Gallionsfigur des nationalen Identitätsverständnisses schlug sich im Mai 1971 in einem Bundesratsbeschluss zur Entwicklung der Berggebiete nieder:

Das gesamtwirtschaftliche Entwicklungskonzept für das Berggebiet, wie es durch den BRB vom 5. Mai 1971 genehmigt wurde, bedeutet, dass sich die Eidgenossenschaft inskünftig konsequenter und systematischer als bisher um die in den Berggebieten herrschenden Lebensbedingungen kümmern wird. Als wichtigste Entfaltungsbereiche dieser neuen Politik sind die Landwirtschaft, der Fremdenverkehr, die öffentlichen Finanzen, das Bildungswesen und die Infrastruktur zu nennen. ${ }^{207}$

Der Bundesrat setzte eine Arbeitsgruppe unter der Leitung des Berner Volkswirtschaftsprofessors Paul Stocker ein. ${ }^{208}$ Diese sogenannte Arbeitsgruppe Stokker bezog sich in ihrem Arbeitsbereich unter anderem auch auf Winterbergers Publikationen. ${ }^{209}$ Damit griff sie den Publikationen der alternativen Jugendbewegung vor, die in ihren sogenannten „Alternativ-Katalogen“ von der linken,

203 Schär, Bernhard C.: Bauern und Hirten reconsidered. Umrisse der ,erfundenen Schweiz‘ im imperialen Raum, in: Patricia Purtschert, Barbara Lüthi, Francesca Falk (Hg.): Postkoloniale Schweiz. Formen und Folgen eines Kolonialismus ohne Kolonien (Bielefeld 2012) 315-331, Kreis, Georg: Der ,Stadt-Land-Gegensatz': ein fragwürdiges Erklärungsmuster, in: Pascal Maeder, Josef Mooser (Hg.): Wozu noch Sozialgeschichte? Eine Disziplin im Umbruch (Göttingen 2012) 89-110, 94-97.

204 J. Solchany: Wilhelm Röpke, 43-45.

205 Ebd.

206 A. Franc: Wie der Vorort.

207 Stocker, Paul: Leitlinien für die Berggebietsförderung (Bern 1973), 2.

208 Stocker, Paul: Grundlagen zu den Leitlinien für die Berggebietsförderung (Bern 1972), VII. 209 Ebd., 677. 
entgegengesetzten Seite her in praktisch derselben Wortwahl wiederum unter dem Titel „Berggebiete“ 1978 die „Unterentwicklung in der Schweiz“ anprangerte. ${ }^{210}$ Auch innerhalb des Schweizerischen Bauernverbands sollte es rumoren, als sich in den 1970er-Jahren die Klein- und Bergbauern als eigenständige Kraft mit viel Rückenwind aus der nicht-landwirtschaftlichen Bevölkerung positionierten. 1980 konstituierten sich die Kleinbauern schliesslich als eigenständiger Verband. ${ }^{211}$

Der Abschied von der Makroökonomie war jedoch gerade im Hinblick auf Strahms Ausbildung an der Universität Bern nicht so offensichtlich, wie dieser im Rückblick schreibt und wie es aus Sicht der internationalen akademischen Makroökonomie der Fall zu sein scheint. So betreute Stocker Strahms Diplomarbeit zum effektiven Zollschutz der Schweiz und arbeitete selbst in dieser Zeit an einer Studie über den Schutz der Berggebiete. ${ }^{212}$ Auch ganz im Sinne der Kontinuität hat somit ein Professor an der Universität Bern bereits 1971 eine Studie zu einem Thema vorgelegt, das einige Jahre später von der Dritte-Welt- und der Umweltbewegung aufgenommen werden sollte. Der Schutz der Berggebiete passte zum internationalen Slogan Small is beautiful, aber nicht nur: Dieses Thema war ein gewichtiges Anliegen der neokonservativen Bewegung der Schweiz und fand Zustimmung bei einer sehr breiten Bevölkerungsschicht. Da die Dritte-Welt-Bewegung die „Abkopplungsthese“ von Beginn an adaptierte, verschwand der Widerspruch zwischen dem Schutz der Berggebiete im Inland und der Unterstützung der Dritten Welt. Eine weitere Theorie, jene der „Peripherie im Inland“, legte umso mehr die Grundlage für die aktive Unterstützung der Berggebiete im Inland durch die Dritte-Welt-Bewegung. Diese neue Theorie war jedoch eingebettet in diverse äussere Entwicklungen im Umfeld der NGO.

Einerseits war die EvB vom Thema Umweltschutz überrollt worden und setzte sich nun unmerklich genauso für den biologischen Landbau im Inland und die Kleinbauern in der Schweiz ein wie für die Dritte Welt. Andererseits war sie durch ihren Einbezug in die Gesetzesentwicklung von der ursprünglichen Forderung Trade, not Aid in den Bereich der Entwicklungshilfe gedriftet. Von ihrem ursprünglichen Kernthema, der Schaffung des Marktzugangs für Entwicklungsländer durch die Veränderung der wirtschaftlichen Strukturen der Schweiz, hatte sie sich verabschiedet. Dieser Schritt war auf zwei Ebenen erfolgt, auf einer theoretischen und auf einer praktischen. Letztere zeigte sich für Anne-Marie Holenstein,

210 Dezentrale: Alternativ-Katalog 3, 577-580.

211 Moser, Peter: Schweizerische Vereinigung zum Schutz der kleinen und mittleren Bauern (VKMB), in: Marco Jorio (Hg.): Historisches Lexikon der Schweiz (Basel 2002-2014) http://www. hls-dhs-dss.ch/textes/d/D16465.php (27.11.2012), P. Moser: Stand der Bauern, 282-307.

212 P. Stocker: Leitlinien, P. Stocker: Grundlagen. 
als sie im Rahmen der Spendenaufrufe an politische Gemeinden sah, dass diese auch im Inland spenden wollten. ${ }^{213}$ Im April 1971 hatte die EvB eine Aktion gestartet: Die politischen Gemeinden sollten einen Teil ihres Budgets an die Entwicklungshilfe spenden. ${ }^{214}$ Damit vertrat die EvB zwar den Punkt 13 der Erklärung - die freiwillige Spende -, allerdings hatten die Initianten sich unmittelbar nach dem Bekanntwerden der Erklärung beklagt, dass ihre ganzen Forderungen in den Medien einzig auf die Spende reduziert würden. ${ }^{215}$ Mit der Gemeinde-Aktion verstärkte die EvB diese Wahrnehmung nun selber, allerdings war die Aktion auch ein wichtiger Seismograf hinsichtlich der Zukunft. In vielen Gemeinden zeigte sich, dass die Bevölkerung durchaus bereit war, an arme Länder zu spenden, dass dies aber nur in Kombination mit einer Spende an die „Armen“ im Inland, in der Schweiz, befürwortet wurde. Darunter verstand die Bevölkerung nicht etwa Obdachlose in Schweizer Städten, alleinerziehende Frauen oder ausländische Saisonniers, sondern Schweizer Bergbauernfamilien. So erhielt die während des Zweiten Weltkriegs gegründete NGO Schweizer Berghilfe dank der Dritte-WeltBewegung unverhofft mehr Spenden. ${ }^{216}$ Die EvB ihrerseits gelangte zur Erkenntnis, dass die Dritte Welt und die Berggebiete in der Schweiz in der Wahrnehmung ihres Zielpublikums untrennbar miteinander verknüpft waren. Auch die UppsalaKonferenz des ÖRK von 1968 hatte diese Entwicklung vorweggenommen. Sie propagierte, je fünf Prozent des kirchlichen Zehnten für die Entwicklungshilfe im In- und Ausland $\mathrm{zu}$ geben. ${ }^{217}$ Diese Haltung wurde also nicht nur von der Schweizer Bevölkerung vertreten, sie fand auch Ausdruck in internationalen Gremien. Als der rechtskonservative Nationalrat James Schwarzenbach in der Debatte um das Gesetz über die Entwicklungszusammenarbeit forderte, dass auch die Schweizer Berggebiete unterstützt werden sollten, sprach er nicht nur seiner kleinen rechten Bewegung, sondern der breiten Bevölkerung ganz Europas aus der Seele. Dies war auch den Sekretären der EvB klar. Holenstein hatte dies bereits um 1971 auf zahlreichen Gemeindeversammlungen gehört, und Rudolf Strahm beobachtete, dass der Professor, der ihn betreute, im Auftrag des Bundes eine Studie zum Schutz der Berggebiete verfasste.

Es war somit ein kleiner und scheinbar kohärenter konzeptioneller Schritt, die Theorie der „Peripherie im Inland“ ins EvB-Konzept zu übernehmen. Wiederum kümmerte sich Rudolf Strahm um die Übersetzung der Theorie in einfache Broschüren mit Infografiken.

213 A.-M. Holenstein-Hasler, R. Renschler, R. H. Strahm: Entwicklung heisst Befreiung, 47-48. 214 SozArch, EvB, Ar 430.25.2. Aktion „Politische Gemeinden und Entwicklung“ 1970 - 1973.

215 A.-M. Holenstein-Hasler, R. Renschler, R. H. Strahm: Entwicklung heisst Befreiung, 25.

216 Ebd., 47-48.

217 Ebd., 48-49. 
gezeichnet worden sind: Die Peripherie ist Pohstoff- und Arbeitskräftelieferant, die Terms of Trade verschlechtern sich, die Netropole schöpft den Surplus (grob: die Ersparnisse) ab, sie wächst auf Kosten der Peripherie.

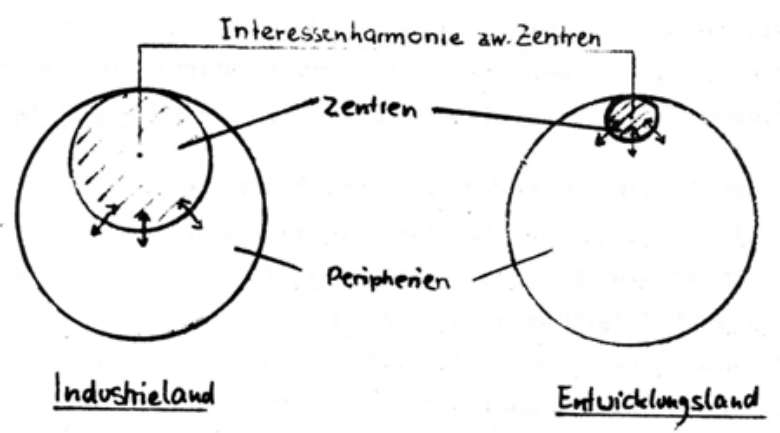

Peripherie ist hier nicht nur im geographischen, sondern auch im sozialen Sinne verstanden. Sie umfasst die sozialen :arginalgrumen, die vom Wachstum überfahrenen urbanen Klassen, das städtische Lumpenproletariat, die Slumbewohner. Sie ist sozusagen die vierte Velt in der ersten und dritten. Es ist auch deutlich, dass die Peripherie nicht nur in den unterentwickelten Ländern, sondern auch in den industrialisierten Wirtschaftsräumen im Norden vorkormt. Yan denke an die unterentwickelten Gebiete in Süditalien, an die Entleerungsräume in den Alpentälern, in Elsass-Lothringen, in der Normandie usw. Man

Abb. 8: Peripherie im Inland (1974)

Nachdem Strahm sich zunächst in seinen populärwissenschaftlichen Publikationen auf seine Diplomarbeit gestützt hatte, bezog er sich danach auf Literatur aus Forschungsinstituten in Entwicklungsländern oder auf westliche ausserakademische Literatur. ${ }^{218}$ Im Gegensatz zu seiner Diplomarbeit wurden seine weiteren Publikationen nicht mehr akademisch korrigiert und kontrolliert. Die erste theoretische Neuerung und somit das erste NGO-,,Wissenschaftsoutput“ - und damit auch die erste Produktion der EvB als Think-Tank - war die Verbreitung des Grundsatzes der „Abkopplung“ und danach noch bedeutender jene der „Peripherie im Inland“. ${ }^{219}$ Das Modell der „Peripherie im Inland“ oder das auf La-

218 A.-M. Holenstein-Hasler, R. Renschler, R. H. Strahm: Entwicklung heisst Befreiung, 151, M. Schär: Strukturveränderungen statt Entwicklungshilfe, 71.

219 R. H. Strahm: Beziehungen Schweiz Dritte Welt. 
teinamerika bezogene, von André Gunder Frank und Rodolfo Stavenhagen propagierte Modell der inneren Kolonisation, korrigierte das ursprüngliche nationalökonomische Prebisch-Singer-Modell. Neu standen sich somit nicht die Industrie und das Entwicklungsland gegenüber, sondern es gab sowohl in Entwicklungs- wie in Industrieländern Zentren und eine Peripherie. Strahm korrigierte sich nun 1974 offiziell selbst:

Es ist in der Tat ein Fehler der bisherigen Theorien, dass sie die unterentwickelten Länder als homogene Gebilde behandelt haben. (Diese Feststellung betrachte ich durchaus auch als Selbstkritik, z.B. gegenüber meinem Werkbuch Industrieländer-Entwicklungsländer von 1971). ${ }^{220}$

Diese neue Sichtweise, die nun klar von der nationalökonomischen Sicht eines Landes als volkswirtschaftliche Einheit und damit von Prebisch und Singer und den Wirtschaftswissenschaften abwich, brachte denn auch eine Neufassung des Begriffes der Solidarität mit sich. Und zwar eine „Neufassung des Solidaritätsbegriffs - im Sinne von ,Die Ärmsten fördern““, schreibt Strahm. ${ }^{221}$ Damit waren nun nicht mehr die ärmsten Nationen gemeint, sondern die relativ Ärmsten innerhalb der Nationen:

Die Symptome der Unterentwicklung zeigen sich nicht nur in den Entwicklungsländern, sondern auch in der ,entwickelten' Schweiz. Die relative Verarmung benachteiligter Regionen (Berggebiete) gegenüber den Industrie- und Verwaltungszentren, die sich ständig verschärfende Besitzkonzentration, die Abwanderung in die Städte usw. sind auch in der Schweiz Anzeichen von Unterentwicklung - derselben Unterentwicklung wie in der Dritten Welt, nur überdeckt durch einen Reichtum, der es gestattet, die sozialen Härten dieses Zustandes zu mildern. ${ }^{222}$

Diese „Neufassung des Solidaritätsbegriffs“ war die wohl bedeutendste konzeptionelle Neuerung, welche die Bahn nun freimachte für den westlichen Neoprotektionismus. Sie machte aber auch den Weg frei für die Generation der Schweizer 68er-Aktivistinnen und -Aktivisten, die sich nun von ihrer selbstauferlegten „Schuld“ als Bürger des „heimlichen Imperiums“ Schweiz nicht befreien, aber immerhin erleichtern konnten. ${ }^{223}$ Die Solidarität mit den eigenen Schweizer Bergbauern oder sogar die Verpflichtung, selbst einen Sommer auf einer Alp

220 Ebd., 9.

221 A.-M. Holenstein-Hasler, R. Renschler, R. H. Strahm: Entwicklung heisst Befreiung, 144.

222 A. Bänziger: Entwicklungsland Welt - Entwicklungsland Schweiz, 13.

223 L. Stucki: Das heimliche Imperium. 
mitzuarbeiten, verschaffte dem „Unbehagen im Kleinstaat“ Linderung. ${ }^{224}$ Der Schwerpunkt der Systemkritik hatte sich von der zwischen den Nationen bestehenden Ungerechtigkeit auf die Ungerechtigkeit innerhalb der Nationen verschoben. Um diese Ungerechtigkeit im Inland zu beheben, wurde der Neoprotektionismus, kaschiert als Schutz der „Peripherie im Inland“, in der Dritte-WeltBewegung salonfähig.

Allerdings war der Fokus auf die Berggebiete zuerst in der Bevölkerung auszumachen, während in der Bewegung selbst noch das klassische marxistische Vokabular mitschwang. Mit der „Peripherie im Inland“ definierte Strahm 1974 die „sozialen Marginalgruppen“ sehr interessant und für den späteren Anti-Globalisierungsdiskurs stilprägend als „die vom Wachstum überfahrenen urbanen Klassen“.225 Die Angehörigen der Wachstums- und Industriegesellschaft im Westen wurden somit Mitte der 1970er-Jahre konzeptuell von Tätern zu Opfern. Nicht die Bürger der Industrienationen als Einheit wurden nunmehr in die Pflicht genommen, sondern nur noch die Vertreter des Zentrums der Industrienationen, die Eliten. Mit dem „Peripherie-im-Inland-Modell“ bzw. mit der Anwendung eines ursprünglich für lateinamerikanische Staaten entwickelten Modells der inneren Kolonisation erhielten nun doch überraschend viele Schweizer Bürgerinnen und Bürger den Peripherie-Status und damit die Absolution. Nachdem nicht nur Bergbauern, sondern auch Arbeiterinnen und Arbeiter sowie „vom Wachstum überfahrene urbane Klassen“ von der Verantwortung ausgenommen waren, blieb faktisch nur noch eine sehr kleine Gruppe im „Zentrum“ übrig. Diese kleine Gruppe von Leuten, die überhaupt noch in die Verantwortung genommen werden konnte, waren die Vertreter der multinationalen Firmen und Banken. Die direkte Einforderung von Verantwortung an die Adresse der multinationalen Firmen und die Finanzindustrie bildete ab Mitte der 1970er-Jahre eine Konstante und Kernkompetenz der EvB. Die Gruppe der Leute, die mit der Formulierung „unsere Mitverantwortung“ im dem Manifest von 1968 in Punkt fünf gemeint waren, hatte sich mit Hilfe des „Peripherie-im-Inland-Modells“ drastisch reduziert. ${ }^{226}$

Es ist nicht so, dass die akademische Nationalökonomie der 1970er-Jahre sich nicht mit Einkommensunterschieden innerhalb der Nationen befasst hätte. Im Gegenteil: Zahlreiche universitäre Ökonomen der 1970er-Jahre vertraten für die Entwicklungsländer etwa das Konzept der arbeitsintensiven Industrialisierung bzw. der keynesianischen Defizitausgaben. ${ }^{227}$ Wie Speich Chassé aufgezeigt hat,

224 K. Schmid: Unbehagen im Kleinstaat.

225 R. H. Strahm: Beziehungen Schweiz Dritte Welt, 10.

226 https://www.publiceye.ch/fileadmin/files/documents/Ueber_uns/EvB_1968_0.pdf (28.3. 2018). Siehe auch SozArch, EvB, Ar 430.25.1. EvB, Anfangszeit: Die Erklärung von Bern, März 1968.

227 G. Austin: The Developmental State. 
fanden auch innerhalb der Ökonometrie, der technischen Messung des Wachstums und der volkswirtschaftlichen Leistung, ab den 1970er-Jahren Neuerungen statt, mit dem Ziel, nicht das gesamtwirtschaftliche Wohl, sondern das Wohl des Einzelnen besser statistisch sichtbar zu machen. ${ }^{228}$ Die akademische Ökonomie verwendete allerdings nicht eine Ideologie, um die Ungleichheit innerhalb von Nationen zu messen, sondern den Gini-Koeffizienten. Damit liess sich nicht nur die Ungleichheit innerhalb einer Nation statistisch messen, sondern auch die innere Ungleichheit verschiedener Nationen vergleichen. Damit nicht genug: Die akademische Ökonomie hörte nicht auf, weiterhin die Wohlstandunterschiede von Nationen zu messen, und stellte dabei in den 1970er-Jahren ein Öffnen der Schere zwischen Industrie- und Entwicklungsländern fest. So ungenau, umstritten und fraglich die Berechnung des Bruttosozialprodukts auch war, die „Divergence, big time“ war spätestens in den 1980er-Jahren nicht mehr von der Hand zu weisen und die „unterste Milliarde“ zeigte nicht Wachstum, sondern schrumpfte und fiel immer weiter hinter die reichsten Länder, zu denen auch die Schweiz gehörte, zurück. ${ }^{229}$ So wies die Schweiz in den 1980er-Jahren etwa ein 145 Mal höheres Bruttoinlandprodukt pro Kopf aus als Tansania, das einstmalige Sehnsuchtsland der Dritte-Welt-Bewegung. ${ }^{230}$ Die statistischen Unterschiede präsentierten sich derart fatal, dass sie für Aktivisten wohl kaum noch erträglich waren. Kein Wunder, sprach etwa EvB-Vorstandsmitglied Gilbert Rist der Ökonomie ihren Status als Wissenschaft schlicht ab. ${ }^{231}$ Doch die paraakademische Theorie der „Peripherie im Inland“ stellte bereits Mitte der 1970er-Jahre eine vermeintliche Gleichheit her zwischen randständigen sozialen Gruppen im Norden und im Süden, während faktisch die Schere auch zwischen dem Wohlstand dieser Peripherien der verschiedenen Nationen auseinanderging. Oder anders ausgedrückt: Je grösser der Einkommensunterschied zwischen einem Kleinbauern in der Schweiz und in Afrika, umso blumiger zeichnete die Dritte-Welt-Bewegung die vermeintliche Solidarität zwischen diesen. Der neue Solidaritätsbegriff entbehrte nun jeglicher wissenschaftlichen Basis, legitimierte aber die Zusammenarbeit der EvB mit NGOs, die sich für inländische Anliegen einsetzten, wie etwa der Schweizer Berghilfe oder Interessensgruppen für den biologischen Landbau, aber genauso die Kooperation mit Gewerkschaften. Die Theorie der „Peripherie im Inland“ legitimierte die Unterstützung von Benachteiligten im

228 D. Speich Chassé: Erfindung des Bruttosozialprodukts, 210.

229 L. Pritchett: Divergence, Big Time.

230 Siehe dazu ein Vergleich der beiden Länder auf der Webseite der Weltbank (http://data.world bank.org/indicator/NY.GDP.PCAP.CD?locations=CH-TZ).

231 M. Nobs-Margairaz: L’Institut africain, 87. Siehe für spätere Jahre G. Rist: L'économie ordinaire, G. Rist: Le développement, 426-435. 
Inland. Sie öffnete Tür und Tor für den Agrarprotektionismus gegenüber Importen aus Entwicklungsländern, für den Schutz der Schweizer Arbeiter vor Werkverlegungen in den Süden und für eine vermeintliche Solidarität zwischen Bergbauern in der Schweiz und Kleinbauern im Süden. ${ }^{232}$

Strahm widerrief nicht nur schriftlich seine frühere Haltung zum Thema Zentrum und Peripherie, auch die EvB kommunizierte diese Konzeptänderung schriftlich ihren Mitgliedern. Der Rundbrief von 1975 hielt fest:

Bis heute konzentrierten sich Informationen und Aktion der EvB auf die armen Massen und die Unterdrückten in den Entwicklungsländern. Mit dem neuen Entwicklungskonzept, das auf dem Zentrum-Peripherie-Modell beruht, können wir uns nicht mehr auf Aktionen beschränken, die nur ferne Völker betreffen. ${ }^{233}$

Das neue Verständnis von Solidarität und die abseits der akademischen Ökonomie erfolgte Neulesung des Zentrum-Peripherie-Modells war die Grundlage für den Aufstieg des Kleinbauern als Idealfigur der Dritte-Welt-Bewegung. Dank der starken Schwerpunktarbeit der EvB im Bereich Schul- und Erwachsenenbildung fand der Kleinbauer auch sehr früh Eingang in die Schulstuben. Genauer gesagt: Der Kleinbauer aus Jeremias Gotthelfs Erzählungen oder der Bergbauer der Geistigen Landesverteidigung wurde in einem neuen Kleid wieder aufs Feld geschickt. Dazu Regula Renschler:

Die Unterrichtsziele waren Verständnis wecken für Bauernfamilien in Kleinbetrieben in ihren unterschiedlichen Umfeldern und in ihren anderen Lebensweisen sowie Einsicht in Mechanismen zu gewinnen, die dazu führten, dass Kleinbauern überall mit dem Überleben zu kämpfen hatten. Dahinter stand die Zentrum-Peripherie-Theorie, mit der sich in den siebziger Jahre die Verarmung ländlicher Gebiete plausibel erklären liess. ${ }^{234}$

Ausser Strahm verstanden die meisten Vertreterinnen und Vertreter der Bewegung nicht wirklich, dass sie sich von der Prebisch-Singer-These entfernt hatten und ein anderes Zentrum-Peripherie-Modell meinten, das nicht akademisch abgesichert war. Gerade in der Schweiz waren Kleinbauern in den 1960er- und 70er-Jahren nicht verarmt, sondern in den Industriestaat abgewandert, wo lukrativere Verdienstmöglichkeiten warteten. Die Schweizer Bauern hatten und haben in der Wohlstandsgesellschaft der Nachkriegszeit die Freiheit der Wahl. Der Wohlstand und das System der freien Marktwirtschaft ermöglichte den Bäuerinnen und Bauern, in ein angenehmeres Leben abzuwandern, und erlaubte es jungen

232 Siehe dazu auch K. J. Kuhn: Entwicklungspolitische Solidarität, 229.

233 A.-M. Holenstein-Hasler, R. Renschler, R. H. Strahm: Entwicklung heisst Befreiung, 192.

234 Ebd., 234. Siehe dazu auch 4.1. Die EvB und die OS3: Bücher und Nahrungsmittel. 
Städterinnen und Städtern, auszusteigen und auf einem Bauernhof im Jura - der den Schweizer Aussteigern vor der Kantonsunabhängigkeit 1978 als „innere Kolonie“ diente - ein autarkes Leben mit Selbstversorgung auszuprobieren. Im Gegensatz zu Bauern in Entwicklungsländern waren in der Schweiz Bauern und junge Aktivistinnen „Free to Choose“, um einen Buchtitel des neoliberalen Ökonomen Milton Friedman zu verwenden. ${ }^{235}$

Zudem waren die Schweizer Bauern im Gegensatz zu jenen in den Entwicklungsländern sozial abgesichert, denn nach 1948 wurde hier der Sozialstaat mit Alters-, Invaliden- und Arbeitslosenversicherung, obligatorischer Unfall- und Krankenversicherung und anderen Sicherungen ausgebaut. Das Landwirtschaftsgesetz von 1952 hatte die verfassungsrechtlichen Grundlagen geschaffen, dass die Landwirtschaft von der Marktwirtschaft ausgenommen werden und der Staat die Landwirtschaft unter seine Fittiche nehmen konnte. Mit dem Berner Volkswirtschaftsprofessor Alfred Amonn oder dem NZZ-Redaktor Richard Ottinger waren vehemente Kritiker dieser Entwicklung bereits Ende der 1960er-Jahre verstummt. ${ }^{236}$ In den 1970er-Jahren fehlten in der Schweizer Öffentlichkeit Kenner und pointierte Kritikerinnen und Kritiker der schweizerischen Landwirtschaftspolitik. So konnte sich das Bild des armen Schweizer Bergbauern in der Öffentlichkeit festsetzen. Die Gleichsetzung der Bergbauern im Inland mit Kleinbauern in Entwicklungsländern brachte jedoch auch eine Abwertung der Figur des Bergbauern mit sich. Hatte etwa Gerhard Winterberger in den 1960er-Jahren den Bergbauern als Symbol des selbstbestimmten, freiheitlichen Lebens gezeichnet, so wurde der Bergbauer nun im Diskurs der Dritte-Welt-Bewegung zum schutzbedürftigen Opfer einer fehlgeleiteten Weltwirtschaft. ${ }^{237}$ Mit Alten, Behinderten oder Migranten wurde der einst so stolze Bergbauer nun von der Dritte-Welt-Bewegung in einen Topf geworfen:

Wer am Schicksal der Schweizer Bergbauern Anteil nimmt, muss auch Anteil nehmen am Schicksal der Menschen in der Dritten Welt. Wer sich umgekehrt mit den Benachteiligten in den Entwicklungsländern solidarisiert, solidarisiert sich auch mit den Benachteiligten in der Schweiz: mit den Alten und den Behinderten, den Bergbauern und den Fremdarbeitern. ${ }^{238}$

Die Emotionen ersetzten statistische Daten. Auf der Ebene der Theorie hatte die EvB Abschied genommen von akademischen, abstrakten Modellen und sich auf

235 Friedman, Milton; Friedman, Rose D.: Free to Choose. A Personal Statement (New York 1980).

236 A. Franc: Wie der Vorort, 144.

237 G. Winterberger: Umstrittene Agrarpolitik.

238 A. Bänziger: Entwicklungsland Welt - Entwicklungsland Schweiz, 14. 
zugängliche Fallbeispiele verlegt, auch wenn dabei die „wissenschaftliche Fundierung“, auf der Strahm stets bestanden hatte, verloren ging. ${ }^{239}$ So floss ein Beispiel der EvB, in dem drei Bauernfamilien, die aus Guatemala, Spanien und der Schweiz stammten, miteinander verglichen wurden, in eine Publikation für den Lehrerservice des WWF ein. ${ }^{240}$ Dabei wurden nicht die makroökonomischen Unterschiede, etwa die stark unterschiedlichen Farm-Gate-Preise, die Agrarsubventionen oder die Schutzpolitik thematisiert, sondern die Gemeinsamkeiten der drei Familien. ${ }^{241}$ Es wird deutlich, wie im Bereich der Lehrerfortbildung die wirtschaftswissenschaftliche Fundierung zugunsten der emotionalen Ebene bereits Mitte der 1970er-Jahre verschwand und somit früher als in den offiziellen Kampagnen der EvB und der Hilfswerke. Eine als Notiz verfasste Liste zeigt auf, welche „Ähnlichkeiten“ zwischen Bauernfamilien in der Schweiz, Spanien und Guatemala bestanden:

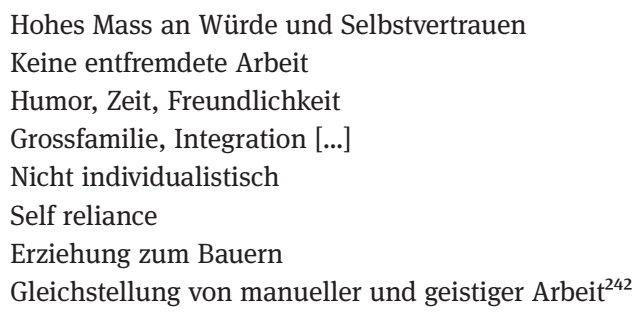

Nicht wirtschaftswissenschaftliche Daten und Grafiken, sondern Emotionen, ein Gefühl der Nähe und Gemeinsamkeit sollten „den Schüler zu einer solidarischen Haltung [...] führen“. ${ }^{243}$

239 A.-M. Holenstein-Hasler, R. Renschler, R. H. Strahm: Entwicklung heisst Befreiung, 127

240 Ebd., 234.

241 Josling, Tim; Anderson, Kym; Schmitz, Andrew; Tangermann, Stefan: Understanding International Trade in Agricultural Products: One Hundred Years of Contributions by Agricultural Economists, in: American Journal of Agricultural Economics 92/2 (2010) 424-446.

242 SozArch, EvB, Ar 430.91.2. Handakten Regula Renschler: Nachlieferung 2009, Teil 2. Lehrerfortbildung/Kurse Kanton Bern, Schriftliche Notizen, undatiert (ca. 1975-77).

243 SozArch, EvB, Ar 430.91.2. Handakten Regula Renschler: Nachlieferung 2009, Teil 2. Lehrerfortbildung/Kurse Kanton Bern, Erziehungsdirektion des Kantons Bern, Zentralstelle für Lehrerfortbildung. Kurzprotokoll, Schweiz-Dritte Welt in Schule und Lehrerfortbildung, Sitzung vom 5.1.1977. 


\subsection{Entwicklungshilfe im Inland und die Gründung der Importgenossenschaft OS3 1977}

Während sich die Einkommensschere zwischen armen und reichen Ländern also ständig vergrösserte, übernahm die EvB die eidgenössische agrarpolitische Rhetorik der „Entwicklungshilfe im Innern“ in ihr Konzept der Nord-Süd-Gerechtigkeit. ${ }^{244}$ Bereits seit 1959 war die Neuorientierung der Landwirtschaft in der Schweiz unter dem Motto der „Entwicklungshilfe“, insbesondere an den Bergbauern, gestanden. ${ }^{245}$ „Obwohl weder die hablichen Mittellandbauern noch die Klein- und Bergbauern sich selber im gleichen Boot wie ihre Berufskollegen in Afrika, Asien oder Lateinamerika sahen, floss diese Perspektive doch zunehmend in die staatliche Agrarpolitik ein“, stellen Werner Baumann und Peter Moser fest. ${ }^{246}$ Da die EvB zum Think-Tank der Dritte-Welt-Bewegung geworden war, äusserte sich dies in einer eigenen agrarpolitischen Agenda. Diese betraf jedoch hauptsächlich das Inland, die „Förderung der ökologischen Landwirtschaft in Entwicklungsländern“ war sozusagen ein Nebenprodukt dieses neuen Schwerpunkts. ${ }^{247}$ Wie stark die eidgenössische „Entwicklungshilfe im Inland“ von der EvB als Think-Tank nicht nur mitgetragen, sondern formuliert und mitgestaltet wurde, zeigt sich nicht nur in den Quellen, sondern wird auch von Anne-Marie Holenstein dargestellt. Auf der Tagung von Gwatt 1974 hatte sie ihr Projekt zum Thema Fleischverzicht vorgestellt, das sie auch im folgenden Jahr betreute. 1975 organisierte Holenstein mit Vertreterinnen und Vertretern anderer Organisationen ein öffentliches Hearing über den Fleischverzicht. Daraufhin formulierte die EvB einen „Katalog agrarpolitischer Forderungen“, der sich ausschliesslich auf die Schweiz bezog. Dieser Katalog beinhaltete folgende Punkte:

- Optimale Nutzung der Grasflächen, vor allem im Voralpen- und Berggebiet

- Förderung des eigenen Futtergetreideanbaus

- Beteiligung der EvB an der demnächst anlaufenden Vernehmlassung für ein neues Tierschutzgesetz mit einschränkenden Massnahmen gegen die Batteriehaltung von Schweinen und Hühnern. ${ }^{248}$

In Zukunft wollte die EvB vermehrt mit der 1972 gegründeten Konsumentengruppe KAG zusammenarbeiten, welche die tierfreundliche und umweltbewusste Nutz-

244 W. Baumann, P. Moser: Bauern im Industriestaat, 28.

245 Ebd., 28-30.

246 Ebd., 28.

247 Dezentrale: Alternativ-Katalog 3, 571.

248 A.-M. Holenstein-Hasler, R. Renschler, R. H. Strahm: Entwicklung heisst Befreiung, 191-192. 
tierhaltung förderte. ${ }^{249}$ Unversehens und wohl unfreiwillig zynisch hatte die EvB ihren Einsatz für die „armen Massen und die Unterdrückten“ in der Dritten Welt auf Schweine und Hühner in der Schweiz ausgeweitet. ${ }^{250}$ Damit lag sie jedoch völlig im internationalen Trend. So setzte sich beispielsweise in dieser Zeit in Grossbritannien auch Elizabeth Stamps, die Kommunikationsbeauftragte von Oxfam, in einem Artikel im „New Internationalist“ gegen Schweinemassenhaltung ein. ${ }^{251}$ Die Dritte-Welt-Bewegung war bereits ab Mitte der 1970er-Jahre nicht mehr von der Bewegung zu trennen, die sich für biologischen Landbau und Tierschutz einsetzte.

Auch der Konsumentenschutz hat sich - im Vergleich zu seinen Ursprüngen in der Vorkriegs- und Kriegszeit - im Verlauf der 1970er-Jahren konzeptionell verändert. ${ }^{252}$ Neue Konsumentengruppierungen wie etwa die KAG entstanden, die bestehenden Konsumentenorganisationen wandelten sich. Der Anteil des Einkommens, das die Konsumentinnen und Konsumenten für Nahrungsmittel ausgaben, verkleinerte sich in der Nachkriegszeit rapide, so dass mehr Geld zur Verfügung stand, um den Konsum ethisch oder politisch zu gestalten. Hier sprang die Umwelt- und Fair-Trade-Bewegung ein und lieferte dem Konsumentenschutz eine neue Aufgabe. So gehörte etwa die bekannte Präsidentin des Konsumentinnenforums Schweiz, Emilie Lieberherr, 1974 zum Schweizer Komitee der EvB. ${ }^{253}$ Die EvB stellte die Forderung an Konsumentenorganisationen, die Fragen der Ökologie, der Beimischung von Antibiotika zu Futtermitteln und das Thema Welternährung gleichwertig zu behandeln wie die Forderung nach möglichst billigen Nahrungsmitteln. ${ }^{254}$ Zahlreiche Studien haben sich auf internationaler Ebene der Geschichte des ethical consumer gewidmet und diese aufgerollt. ${ }^{255}$ An dieser Stelle soll jedoch darauf hingewiesen werden, dass der ethische Konsument im vorliegenden Fall nicht aus dem Nichts entstand, vielmehr hatte sich der politische Bürger in den ethischen Konsumenten verwandelt. Damit war der

249 http://www.kagfreiland.ch/ (13.9.2017).

250 A.-M. Holenstein-Hasler, R. Renschler, R. H. Strahm: Entwicklung heisst Befreiung.

251 Elizabeth Stamp: The End of cheap food, New Internationalist, April 1973, S. 6-8.

252 Eigenmann, Anina: Mit Lobby-Arbeit zum Erfolg? Chancen und Grenzen einer Handlungsstrategie für die ,Soziale Käuferliga der Schweiz', in: Gisela Hürlimann, André Mach, Anja Rathmann-Lutz, Janick Marina Schaufelbuehl (Hg.): Lobbying. Die Vorräume der Macht (Zürich 2016) 155-168, Hilton, Matthew: Prosperity for All. Consumer Activism in an Era of Globalization (Ithaca 2009).

253 SozArch, EvB, Ar 430.10.2. Sitzungsprotokoll vom 23.3.1974. Bürgi, Markus: Lieberherr, Emilie, in: Marco Jorio (Hg.): Historisches Lexikon der Schweiz (Basel 2002-2014) http://www. hls-dhs-dss.ch/textes/d/D6480.php (5.1.2011).

254 A.-M. Holenstein-Hasler, R. Renschler, R. H. Strahm: Entwicklung heisst Befreiung, 191-192. 255 M. Hilton: Prosperity for All. 
ethische Konsument zwar geboren, doch gleichzeitig ersetzte er in den Kampagnen der NGOs den Fokus auf den politischen Bürger.

Der Übergang vom Bürger bzw. von der 1971 eben „geborenen“ Aktivbürgerin zum Konsumenten bzw. zur Konsumentin zeigt sich nirgends deutlicher als in den Alternativkatalogen der Dezentrale, die bereits erwähnt wurden. In den zahlreichen Beiträgen verschiedenster alternativer Gruppen und Organisationen zimmerte die Bewegung in den späten 1970er-Jahren einen Verhaltenskatalog für den Konsumenten. Bezeichnend ist, dass im ersten und zweiten Katalog von 1975 bzw. 1977 das Thema Dritte Welt nicht angesprochen wurde. Hier ging es ausschliesslich um die ökologische und alternative Lebensform. Das Ziel der Bewegung bestand nicht etwa darin, zwischen dem Zentrum und der Peripherie eine bessere Durchlässigkeit herzustellen oder gar der Peripherie zu gleichem Wohlstand wie dem Zentrum zu verhelfen, sondern in der Solidarität mit der Peripherie. Am besten liess sich diese Solidarität mit einem persönlichen Wechsel in die Peripherie herstellen. Das Leben auf entlegenen Alpen, das Selberbauen von Solarheizungen, das Handwerken und die Handarbeit prägten das Selbstbild der Bewegung in der zweiten Hälfte der 1970er-Jahre. ${ }^{256}$ In jener Zeit entstanden zahlreiche landwirtschaftliche Kommunen, die die Vorgaben der Alternativkataloge umsetzten, beispielsweise die noch heute bestehende Gesellschaft Longo maï mit Sitz in Basel. ${ }^{257}$ Die Forderung nach intellektueller, politischer und akademischer Kopfarbeit war der Forderung nach einem Leben in der Natur und der Handarbeit gewichen. Gegen Ende der 1970er-Jahre gab es im Kleinstaat Schweiz mit seinen entlegenen Bauernhöfen im Jura und den zahlreichen Alpwirtschaften eine neue Utopie, welche das zunehmend enttäuschende, langsam in die Wirtschaftskrise abrutschende Tansania ersetzte. Im Alternativkatalog wurde die „Alpwirtschaft“, diese Utopie in der Peripherie, vom Basler Umweltaktivisten Bruno Manser beschrieben, der 1984 noch weiter in die Peripherie zog und beim Naturvolk Penan auf Borneo lebte. ${ }^{258}$ Als „Städter“ hatte er zunächst wie viele seiner Zeitgenossen in den 1970er-Jahren „in dr Alpwirtschaft si Glügg versu$\mathrm{ech}[\mathrm{t}]$ “. 259

Auch die Gründung der Importgenossenschaft OS3 1977 fällt in diese Zeit und in diese konzeptionelle Phase. Die OS3 entstand im Frühling 1974, als die holländische SOS offiziell eine Niederlassung bei einer Privatperson in der Schweiz

256 Dezentrale: Alternativ-Katalog 2, 139-242.

257 A. Schwab: Landkooperativen Longo maï.

258 Weibel, Andrea: Manser, Bruno, in: Marco Jorio (Hg.): Historisches Lexikon der Schweiz (Basel 2002-2014) http://www.hls-dhs-dss.ch/textes/d/D48227.php (5.3.2018).

259 Dezentrale: Alternativ-Katalog 2, 239-240. 
eröffnete. ${ }^{260}$ So war die Organisation Suisse Tiers Monde OS3 im bern-jurassischen Sonceboz eine Privataktion des Sekundarlehrers Jacques Jordan. ${ }^{261}$ Sie bezog von der alternativen Handelsorganisation SOS-Werewinkels in Utrecht Waren aus der Dritten Welt (im Direktimport). Die Importstelle in Sonceboz war also zunächst eine holländische Niederlassung in der Schweiz. Diese holländische Firma SOS wurde von Paul Mejis geleitet, der auch sehr gut Deutsch sprach, später sollte Stefan Durwael übernehmen, der die Fair-Trade-Entwicklung in den Niederlanden wie zuvor Mejis entscheidend prägte. ${ }^{262}$ Mit der neu zu gründenden Schweizer Importstelle sollten in der Schweiz Strukturen für einen alternativen Handel geschaffen werden, die in den Niederlanden bereits bestanden. Nebst dem Input aus den Niederlanden spielte in den 1970er-Jahren vor allem die EvB eine aktive Rolle beim Aufbau der Organisation. Die Vereinigung der Dritte-Welt-Läden Schweiz entstand erst im Frühling 1976. ${ }^{263}$ In den Jahren vorher hatten Vertreterinnen und Vertreter einzelner Organisationen wie etwa der Basler Mission an internationalen Treffen zum Alternativen Handel teilgenommen. ${ }^{264}$

Am 6. Dezember 1975 lud die EvB Hilfswerke und Vertreter von Dritte-WeltLäden zu einem Treffen, um die Gründung einer professionellen Importorganisation zu besprechen. ${ }^{265}$ Die EvB sollte sich danach um die Bewusstseinsbildung kümmern und die Genossenschaft sich vor allem der Geschäfte annehmen, wobei aber die EvB auch bei der zu gründenden Firma darauf bestand, dass diese einen „bewusstseinsbildenden“ Zweck haben sollte. Die Initiierung der OS3 wurde von der EvB angeführt. Sie verstand es, die bürgerlich-kirchlichen Kräfte zu sammeln und für die Gründung einer Firma zu begeistern. ${ }^{266}$ Die Gründungsversammlung der OS3 fand im kirchlichen Zentrum Bürenpark in Bern statt. ${ }^{267}$ Unter den ju-

260 SozArch, Claro 1010.2. OS3 Gründung: Paul Meijs an Rudolf Strahm, 29.3.1974.

261 A.-M. Holenstein-Hasler, R. Renschler, R. H. Strahm: Entwicklung heisst Befreiung, 141.

262 Dam, Peter Van: Moralizing Postcolonial Consumer Society.

263 SozArch, Claro 1011.1. Liste der Gründungsmitglieder der Vereinigung Dritte-Welt-Läden Schweiz (V3WL Schweiz).

264 SozArch, Claro 1010.11. SOS Niederlanden und andere Organisationen: Tagungen, Workshops zu Alternativen Handel 1973-1977.

265 A.-M. Holenstein-Hasler, R. Renschler, R. H. Strahm: Entwicklung heisst Befreiung, 141. SozArch, Claro 1010.2. OS3 Gründung: Liste der Eingeladenen für Konsultation über Importförderderung aus Entwicklungsländern vom 6.12.1975.

266 In der Folge, zu Beginn der 1980er-Jahre, wuchsen die kirchlichen Hilfswerke in diese Rolle hinein und übernahmen die Errichtung der Max-Havelaar-Stiftung Schweiz und damit die Einführung des Fair-Trade-Gütesiegels, während die EvB sich anderen Themen zuwandte. https:// www.maxhavelaar.ch/was-ist-fairtrade/max-havelaar/geschichte.html (24.4.2018).

267 SozArch, Claro 1011.1. OS3. Gründung: Thomas Vatter an die „potentiellen Gründungsmitglieder der Importstelle“, Sonceboz, 17.6.1977. 
ristischen Personen, die als Gründer fungierten, waren etwa der Schweizerische Evangelische Kirchenbund, Brot für Brüder oder der Christliche Friedensdienst. Nur als Gäste anwesend war die Kooperation evangelischer Missionen, das Zentrallager für kunsthandwerkliche Gegenstände aus Übersee der Basler Mission, das Département missionaire sowie das katholische Hilfswerk Fastenopfer. Die Gründer einigten sich auf folgenden Passus:

Die Produktionsarten sollen von traditionellen Fertigkeiten ausgehen und in dezentralisierten Einheiten möglich sein. Als Lieferanten kommen nur genossenschaftlich oder sonstwie in gemeinschaftlicher Selbsthilfe arbeitende Produzenten in Frage. ${ }^{268}$

Die EvB veranlasste die Eintragung als Genossenschaft im Handelsregister und suchte nach einem Geschäftsführer. Die ausgeschriebene Stelle trat Martin Blum an, ein ehemaliger Schweizer Textilkaufmann, der in Südafrika, Argentinien und Brasilien tätig gewesen war. ${ }^{269}$ Damit wechselte ein Kaufmann, der seine Erfahrungen in der klassischen schweizerischen aussereuropäischen Wirtschaft gemacht hatte, in den neu geschaffenen Fair-Trade-Bereich. 1977 wurde die Firma mit der Rechtsform einer Genossenschaft gegründet und die Statuten traten in Kraft. Darunter ist insbesondere Punkt 2 zu erwähnen:

2. Zweck

2.1. Die Genossenschaft bezweckt, den Einkauf von Produkten aus Entwicklungsgebieten und deren Vermarktung in der Schweiz zu fördern.

2.2. Die Genossenschaft bezweckt mit der Vermarktung der Ware eine Information über das betreffende Produkt, seine Herkunft und Preiszusammensetzung, die Umstände seiner Entstehung oder Gewinnung, sowie die Situation des Exportgebietes. ${ }^{270}$

Das Hauptziel der Genossenschaft war der Verkauf von Produkten. Das Produkt sollte als Mittel zur Information dienen, wobei das Ziel darin bestand, das entwicklungspolitische Bewusstsein der Konsumentin bzw. des Konsumenten zu bilden. Aber das entwicklungspolitische Konzept, das der Konsumentin bzw. dem Konsumenten vermittelt werden sollte, änderte sich. Die Botschaft, die mit dem Verkauf von Produkten transportiert wurde, machte einen starken Wandel durch. Bereits bei der Gründung 1977 waren die Botschaften der Verschlechterung der terms of trade und der Notwendigkeit einer Industrialisierung einem neuen Konzept gewichen. Die Ausnützung der 1971 eingeführten Zollpräferenzen wurde

268 SozArch, Claro 1011.1. OS3. Gründung: Grundsätze der Geschäftspolitik.

269 SozArch, Claro 1011.1. OS3 Gründung: Lebenslauf Martin Blum.

270 SozArch, Claro 1011.1. OS3 Gründung: Statuten, Bern, 22.6.1977. 
durch den Konzeptwandel aber bald überflüssig: Für tropische Rohstoffe, die in der Schweiz nicht gediehen, hatten seit jeher keine speziellen Zollschranken bestanden. Da die OS3 nach ihrer Gründung kaum verarbeitete Produkte importierte, ging die ursprünglich Idee, die Zollpräferenzen auszunützen, verloren. Bei der Gründung der OS3 im Jahr 1977 war mit dem Slogan „Jute statt Plastik“ die Förderung von traditionellen Produktionsmethoden, die zu umweltschonenden Produkten und Frauenarbeit führen sollten, bereits zum Primat erhoben worden. Damit folgte die Bewegung und mit ihr die OS3 noch dem international durchaus anerkannten Prinzip der arbeitsintensiven Industrialisierung. Gleichzeitig sollte die Genossenschaft eigentlich eine Alternative $\mathrm{zu}$ Nestlé und anderen Multis darstellen, denen zur gleichen Zeit mit starkem Geschütz - mit dem Slogan „Nestlé tötet Babys“ - unlautere Geschäftsmethoden sowie der unrechtmässige Einfluss auf internationale Organisationen vorgeworfen wurde. ${ }^{271}$ „Eine Weitergabe der Produkte an vorwiegend kommerziell orientierte Weiterverkäufer ist ausgeschlossen“ hiess es daher in den ersten Geschäftsgrundsätzen von 1977. ${ }^{272}$ Es lässt sich jedoch feststellen, dass die eigentliche Art des Wirtschaftssystems bereits um 1980 in den Hintergrund trat und die OS3 sich der Nachfrage anpasste. Bereits wenige Jahre nach der Gründung beschloss die Firma, ihren Anspruch auf den Aufbau eines alternativen Handelssystems fallenzulassen. Stattdessen wollte die OS3 grundsätzlich mit Supermärkten zusammenzuarbeiten, um wachsen zu können. ${ }^{273}$

271 T. Sasson: Milking the Third World.

272 SozArch, Claro 1011.1. OS3 Gründung: Grundsätze der Geschäftspolitik.

273 SozArch, Claro 1010.12. OS3 Gründung: Mario Carera, OS3 bald im breiteren Handel?, November 1979. 